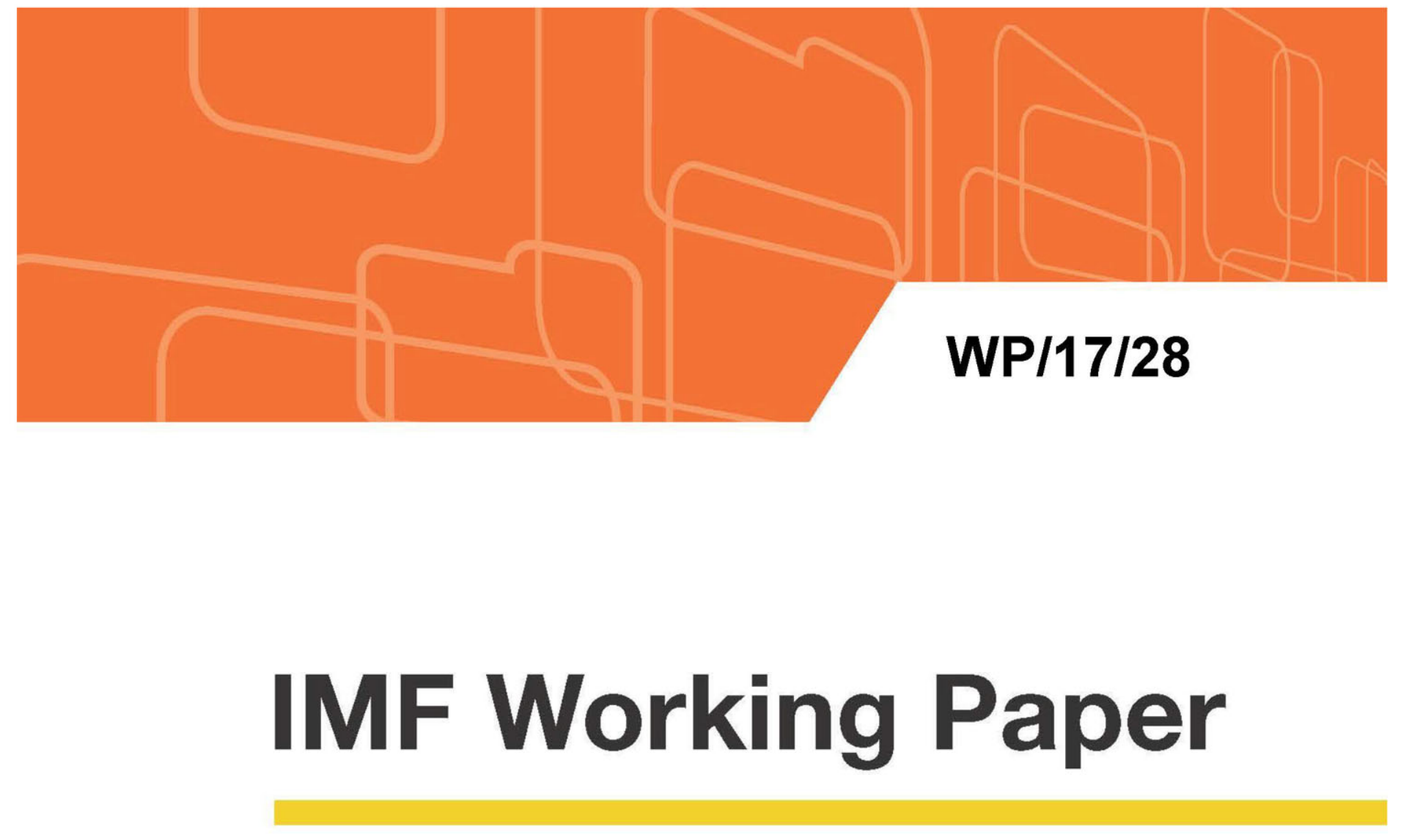

\title{
Exploring the Role of Foreign Investors in Russia's Local Currency Government Bond (OFZ) Market
}

by Yinqiu Lu and Dmitry Yakovlev

IMF Working Papers describe research in progress by the author(s) and are published to elicit comments and to encourage debate. The views expressed in IMF Working Papers are those of the author(s) and do not necessarily represent the views of the IMF, its Executive Board, or IMF management. 


\section{WP/17/28}

\section{IMF Working Paper}

\section{Exploring the Role of Foreign Investors in Russia's Local Currency Government Bond (OFZ) Market}

by Yinqiu Lu and Dmitry Yakovlev

IMF Working Papers describe research in progress by the author(s) and are published to elicit comments and to encourage debate. The views expressed in IMF Working Papers are those of the author(s) and do not necessarily represent the views of the IMF, its Executive Board, or IMF management.

I N T ER N A T I O N A L M O N E T A R Y F U N D 


\title{
IMF Working Paper
}

Strategy, Policy, and Review Department

\section{Exploring the Role of Foreign Investors in Russia's Local Currency Government Bond (OFZ) Market}

\section{Prepared by Yinqiu Lu and Dmitry Yakovlev ${ }^{1}$}

Authorized for distribution by Martin Kaufman

February 2017

IMF Working Papers describe research in progress by the author(s) and are published to elicit comments and to encourage debate. The views expressed in IMF Working Papers are those of the author(s) and do not necessarily represent the views of the IMF, its Executive Board, or IMF management.

\begin{abstract}
Local currency government bonds (OFZ bonds) are an important fixed-income instrument in Russia's financial markets. In this paper, based on granular data, we explore the development of the OFZ bond market with a focus on foreign investors. As this fixed-income market has experienced a liberalization of the domestic trading and settlement infrastructure, and weathered several episodes of market stresses since the 2008-09 global financial crisis, the role of foreign investors can be observed along with these events. What we have found is that foreign investors had influenced the market before they became an important player and since then they have contributed to the development of the market while not necessarily destabilizing it in espisodes of shocks.
\end{abstract}

JEL Classification Numbers: E43; E44; F30; G15

Keywords: local currency government bonds; Russia; financial market development Author’s E-Mail Address: ylu@,imf.org; d.yakovlev@bloomberg.net

\footnotetext{
${ }^{1}$ This paper has benefited from comments from Anastasia Guscina, Martin Kaufman, Oleg Kouzmin, Peter Lindner, Sergei Voloboev, Yi Wu; and excellent research assistance from Viacheslav Ilin. We remain responsible for any remaining errors.
} 


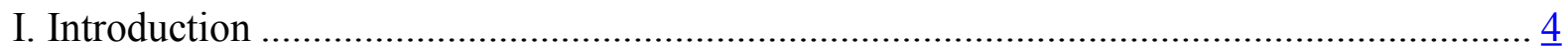

II. The OFZ Bond Market Prior to the Liberalization ………............................................. $\underline{5}$

A. Supply, Demand, and Pricing ................................................................................

B. Foreign Exposure to the OFZ Risk through Proxies ................................................... 14

III. The Process of Liberalization ................................................................................. 18

IV. Markets Adapting to the Liberalization .................................................................... 22

V. Shocks and Market Developments........................................................................ 26

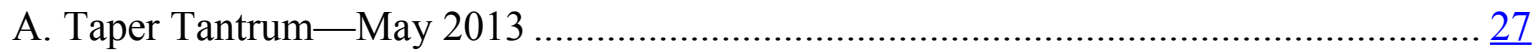

B. The Third Round of Sanctions-Summer 2014 …………………………………..... 29

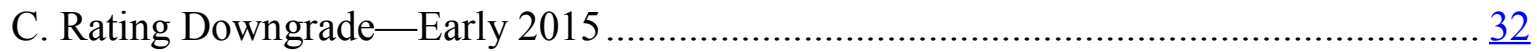

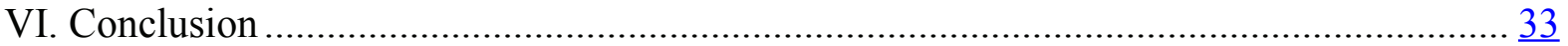




\section{INTRODUCTION}

OFZ bonds, the local currency (LCY) government bonds, feature prominently in Russia's economy and financial markets. The ministry of finance (MOF) regularly auctions OFZ bonds to finance budget deficits, and in rare cases issues them to recapitalize banks or for other one-off financial operations. The Central Bank of Russia (CBR) relies on OFZ bonds for its repo operations to manage systemic liquidity in the banking sector; while correspondingly, domestic banks employ them to manage liquidity. Investors, both in Russia and abroad, hold and trade them for returns. In addition, as the only tradable on-shore rubledenominated government fixed-income instrument, they provide a sovereign ruble domestic yield curve.

Given the roles of OFZ bonds, the OFZ bond market has become an essential part of Russia's financial markets, in which a variety of government agencies and financial market players interact, and are influenced by domestic and global economic perspective and financial market sentiment. Its nature has evolved over time, along with waves of business, commodity, and financial cycles at home and abroad, and has gradually been integrated into the global financial system following the liberalization of the domestic trading and settlement infrastructure (hereafter, refer to "liberalization").

Foreign investors have become ubiquitous in the OFZ bond market. Their share in the market had increased from virtually zero in 2006 to 25 at end-2013 and despite declining to below 20 percent in the first half of 2015, it recovered to 27 percent in September 2016. Such an increase in foreign holdings is not unique in Russia. After the 2008-09 global financial crisis (GFC), driven by systemic economies' accommodative monetary policies and emerging markets' (EMs) stronger growth perspective and enhanced structural frameworks, a global search for yield has led to large capital inflows to LCY government bond markets in EMs (IMF, 2012, Ahmed and Zlate, 2013, Arslanalp and Tsuda, 2012, and Sahay and others, 2014). Increased foreign interest has contributed to lower bond yields (Comelli, 2012; Csonto and Ivaschenko, 2013; and Jaramillo and Weber, 2012) but sometimes higher volatility (Ebeke and Lu, 2015).

While most of the literature implies that foreign investors are entering a LCY bond market that has already existed, the reality is more complicated. One could even argue that foreign investors have actually helped to create the market or at least some segments. The most profound example is the longest segment of the yield curve. In some EMs, ministries of finance started to regularly issue long-term bonds only in response to foreign demand. Hence, instead of being perceived as "guests" to a local market, foreign investors are cofounders of the market. When they create the market, they sometimes also help to integrate the domestic infrastructure into global infrastructure by convincing the authorities of the benefits of doing so. One such case is the OFZ bond market, as its transactions became Euroclearable in February 2013. When infrastructures converge, domestic investors can no longer be considered as the "default" stable investor base, as in the case of a bond sell-off, foreign investors will also buy bonds from other foreign holders that have different investment mandates or strategies. 
In this paper, based on granular data, we explore the development of the OFZ bond market with a focus on foreign investors. This fixed-income market is unique, as it has gone through the process of liberalization and weathered several episodes of shocks, more than most EMs. The behavior of foreign investors can therefore be observed through these events. Before the GFC, foreign investors used cross-currency swaps (XCCY-swaps) as a credit-risk-free instrument to substitute for OFZ bonds; hence the valuation of OFZ bonds was to some extent determined by foreign investors despite their low share of direct participation in the market. In early 2010s and before the liberalization, foreign investors chose to use proxy instruments to replicate the exposure to OFZ bonds, despite the counterparty and liquidity risks involved in proxies. The liberalization process, influenced by the desire of the authorities to make Moscow a financial center, tremendously benefited the OFZ bond market by expanding the investor base. Since then, the market was inflicted by several episodes of shocks; however, it has survived and strived with further structural enhancement and additional new fixed-income products.

The Russian authorities have been prudent in nurturing the development of the OFZ bond market. The credibility of the CBR's inflation targeting framework (IT) or to be more precise, the CBR's determination in adopting the IT helped to anchor inflation expectation and allow forward-looking expectations of interest rates to guide investors' duration allocation of OFZ bonds. The MOF, taking advantage of the buffer role of the Reserve Fund, has avoided financing deficits at all costs and preserved yield curve during market stresses. It has adjusted its issuance policy and instruments to tap into foreign investors and introduced new fixed-income products to cater to new demand. Most importantly, the government has liberalized the OFZ bond market infrastructure despite the pressure arising from the fear of moving liquidity offshore. In general, the credibility of the central bank policy framework and infrastructure liberalization joined forces together and facilitated the bond market development.

The development of the OFZ bond market demonstrates that global financial integration will not reverse. Even without liberalization, foreign investors, searching for yield, would always find ways to get exposure to a local market through derivatives and offshore products. It is crucial for the authorities to understand market force so as to anticipate and manage shocks, and minimize their impact on the economy, aided by prudent and transparent macroeconomic and financial policies. Ultimately shocks will dissipate and new opportunities will emerge, and often this process comes together with the improved policy framework.

\section{The OFZ Bond MARKet Prior to the Liberalization}

The default on Russia's sovereign short-term bonds (GKOs) in 1998 has delayed the development of domestic sovereign bond market by a few years. The re-emergence of this market intensified in the mid-2000s with OFZ bonds becoming its main instrument. 


\section{A. Supply, Demand, and Pricing}

\section{Prior to the GFC}

Prior to the GFC, a couple of supply and demand factors put a lid on the development of the OFZ bond market. From the supply side, blessed with commodity-driven fiscal surplus, the MOF had no financing pressure to issue OFZ bonds. The main purpose of issuing them was to preserve a sovereign yield curve (the so-called technical reasons, MOF, 2011). Receipts from bond issuances were used to retire external debt (Drobyshevskiy and others, 2009).

From the demand side, the negative real OFZ bond yields were unattractive to local institutional investors and other local long-term investors (Chart 1). Instead, investors preferred to hold higher-yield corporate bonds, contributing to the increased stock of corporate bonds while the volume of the outstanding OFZ bonds remained broadly flat (Chart 2). In this environment, the State Pension Fund of Russia (SPFR) became one of the main investors of OFZ bonds as dictated by its investment policy.
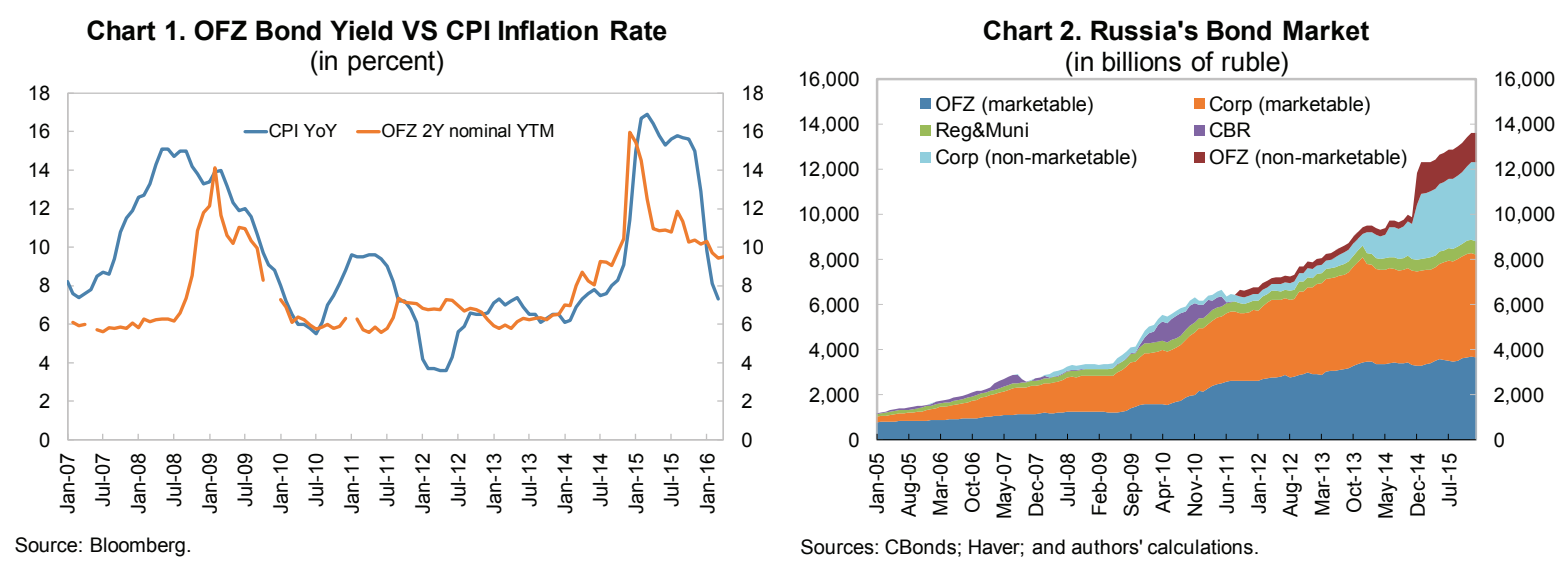

Many domestic banks either found OFZ bonds unattractive or could not afford to hold more beyond the liquidity and regulation purposes. Prior to the GFC, positive growth prospects and high profitability in Russia's banking sector attracted FDI inflows and led to high price to book (P/B) ratios (Charts 3 and 4). As the booming economy offered a large room for loan growth amid high lending rates and low credit risk (Charts 5 and 6), any sizable long-term allocation to low-yield OFZ bonds would reduce a bank's $\mathrm{P} / \mathrm{B}$ ratio and market value. On the other hand, many banks below the top-20 rank could not afford to hold more OFZ bonds, as their costs of funding were often only slightly below or even above OFZ bond yields. As a consequence, both large and small banks in Russia limited their holdings of OFZ bonds (often the off-the-run ones) to their needs of managing liquidity and meeting regulatory requirements (Noel and others, 2006). 
Chart 3. FDI Equity Inflows to Russian Banks (in millions of US dollars)

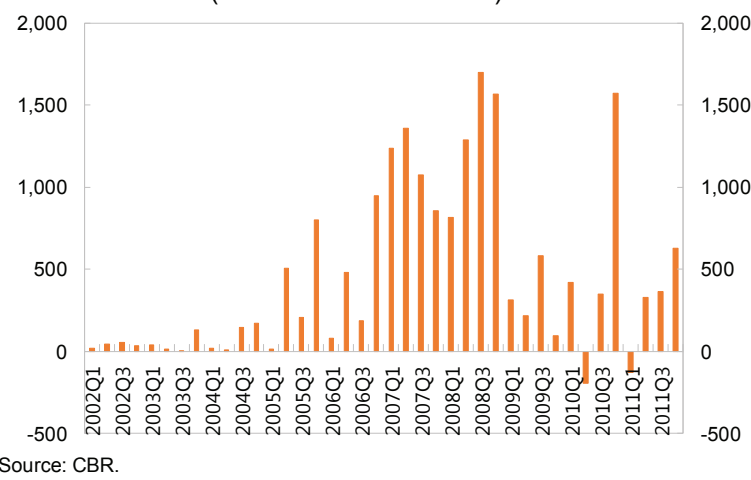

Chart 5. Lending Rate VS OFZ Yields (in percent)

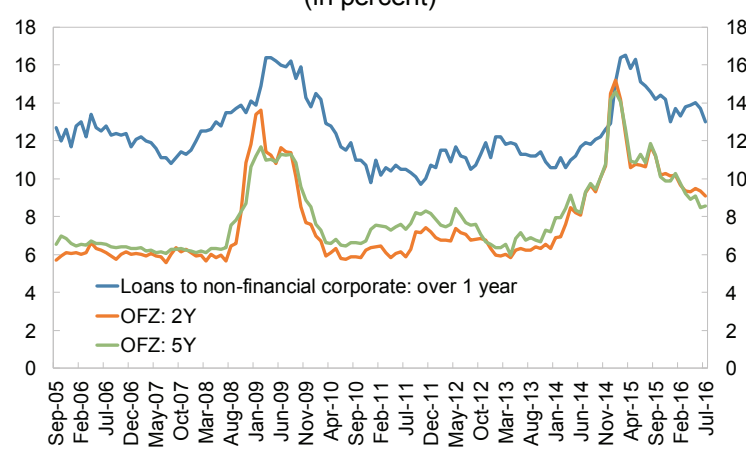

Sources: Haver; and authors' calculations.
Chart 4. Russian Banks: Price-to-Book Ratios

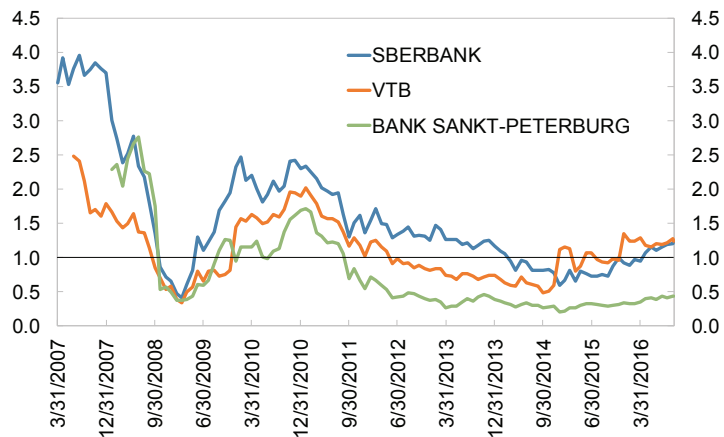

Sources: Bloomberg; and authors' calculations.

Chart 6. Overdue Rate of Loans to Non-financial Corporate

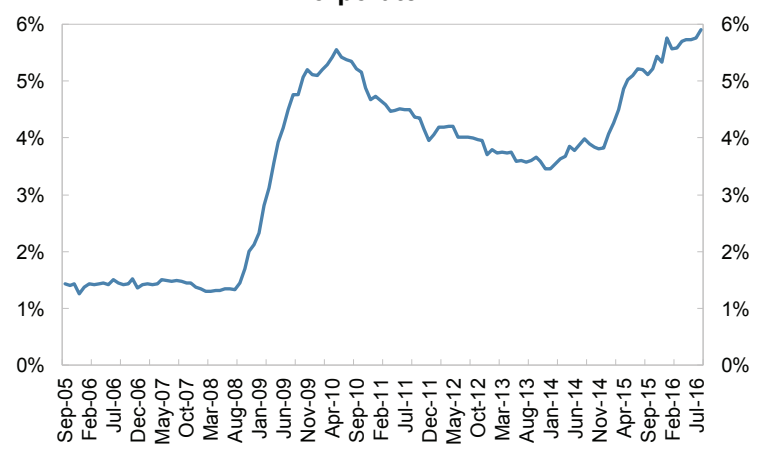

Sources: Haver; and authors' calculations.

Direct foreign holding of OFZ bonds was negligible prior to the GFC. Its share was estimated at 1-3 percent (Euromoney, 2012). For investors following indices, only a small portion of OFZ bonds were included in the J.P. Morgan Government Bond IndexEmerging Markets (GBI-EM) indices. ${ }^{2}$ The bulk of the outstanding OFZ bonds were in the form of amortizable bonds with complex and irregular coupon schedules; while only fixed-rate bullet bonds are eligible for GBIEM indices. On the top of this, market accessibility - the main entry requirement for the indices - was affected by high transaction Chart 7. Breakdown of Eurobond Placements by Industry (in billions of US dollar)

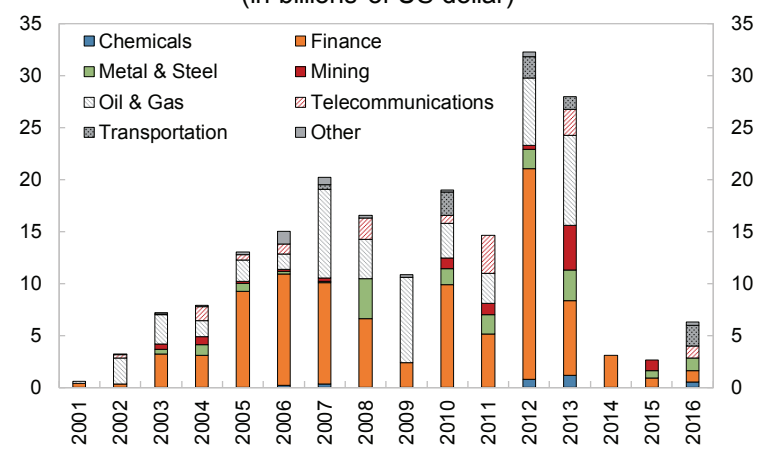
costs and low market liquidity.

\footnotetext{
${ }^{2}$ As in any EM LCY bond markets, there are two types of foreign investments: benchmark-driven and unconstrained. Benchmark-driven investors are those who invest in countries through a fund that tracks a benchmark index. For EM LCY government bond markets, the most important benchmarks are GBI-EM indices. Unconstrained investors are those not restricted by index considerations. As pointed out by Sienaert (2012) and Arslanalp and Tsuda (2015), benchmark-driven investors could provide a stable source of funding. However, they could be a source of vulnerability, as they may introduce a high degree of similarity in their behavior (Raddatz and others, 2015; Miyajima and Shim, 2014).
} 
Despite low foreign ownership, the valuation of OFZ bonds was to some extent determined by foreign investors in other segments of the fixed-income market. This phenomenon was caused by external FX borrowings by large Russian corporates (Chart 7).

In order to attract a sizable amount of borrowing in ruble, large Russian corporates often conducted a 3-stage transaction, with each stage catering to a different group of investors:

(a) Issue an FX-denominated Eurobond, i.e., sell credit risk on global markets;

(b) Swap the FX-denominated payments into ruble-denominated payments by using an XCCY-swap or a sequence of non-deliverable forwards (NDFs);

(c) Sell FX proceeds from the Eurobond in the local spot FX market to obtain rubledenominated liquidity.

Whether to conduct steps (b) and (c) depends on industrial types of corporates, especially the existence of natural FX hedge. For example, the oil and gas companies would only swap a small portion of their debt into ruble as their revenue streams create a natural FX hedge to their liability; while the telecoms or transportation companies would swap almost all of their debt into ruble.

At the stage (a), foreign investors would price credit risk by setting credit spreads to US treasury according to the prevailing global appetite for EM corporate bonds; at the stage (b), another group of foreign investors would price the remuneration required to hold the exposure to ruble-currency risk, i.e., the implied ruble yields of XCCY-swaps and NDFs.

The split of risks at stages (a) and (b) among different groups enabled Russian corporates to cater to a wider spectrum of investors. The stage (a) allowed foreign investors to buy different corporate issuers to diversify credit risk without bearing either ruble currency or ruble interest rate risks. Such risk exposure cannot be achieved by holding rubledenominated corporate bonds alone. Transactions at the stage (b) were standardized ones and close to credit-risk-free, as the expansion of XCCY-swaps and NDFs transactions had created a ruble-denominated fixed-income instrument. Essentially, it was foreign investors and Russian subsidiaries of global investment banks that laid the foundation and became the core investors for a global fixed-income instrument with supply originating from Russia.

Russian domestic banks were also borrowing abroad in the low risk environment prior to the GFC. To fund the growth of smaller corporates, which were unable to attract funds abroad, banks got funding abroad to obtain ruble funding using the same 3 -stage process.

As an OFZ bond could be substituted by a synthetic position of a high quality US dollar denominated bond and an XCCY-swap, the OFZ yields became naturally close to the XCCYswap yields, broadly in line with the covered interest parity (CIP) (Chart 8). When all the components of the effective cost of synthetic ruble borrowing were determined or significantly affected by foreign investors (i.e., credit spread to US treasury, and remuneration for bearing FX and interest rate risks), the positive outlook - good prospects of Russia's economy and the depreciation of the US dollar against the ruble-led to the low 
cost of funding of large Russian corporates and banks. This had translated into low OFZ bond yields, as the MOF would not borrow at a cost higher than those borne by Russian corporates. Inflation was not priced in OFZ bonds, as reflected by the negative real OFZ yields prior to the GFC (Chart 1). OFZ yields converged to those of USD-denominated Russian sovereign Eurobonds, as the expected appreciation of the ruble made the premium for local currency and interest rate risks negligible (Chart 9).
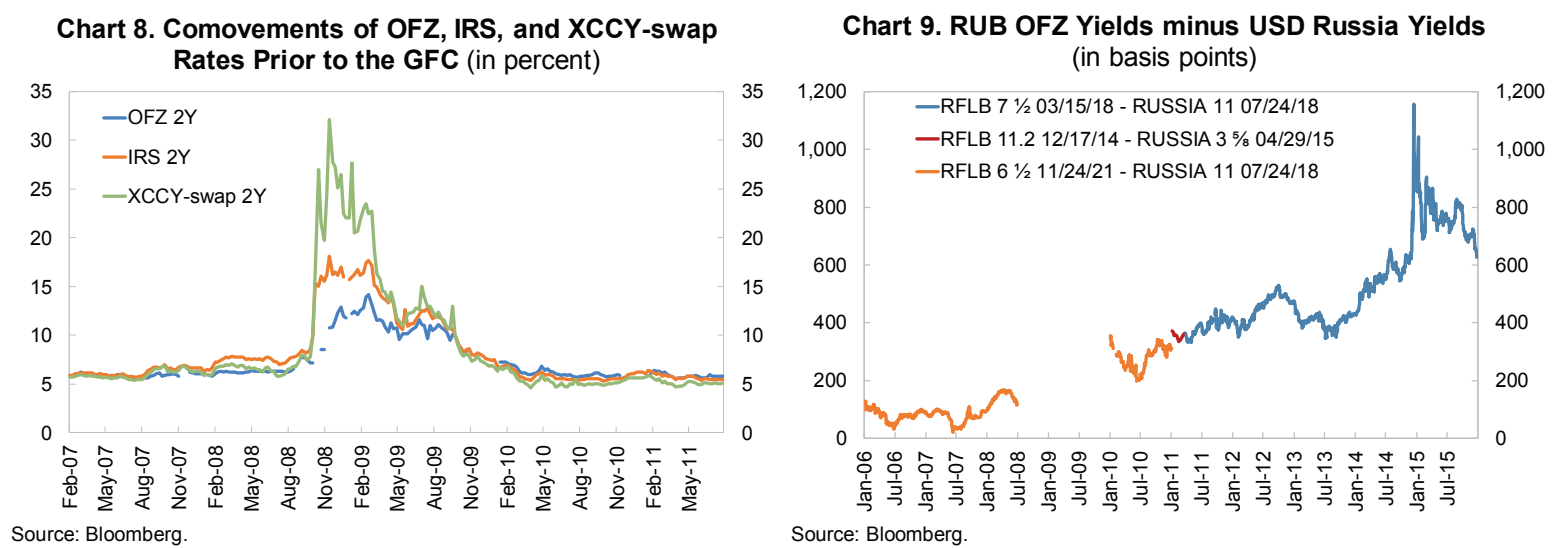

The money market was also influenced by XCCY-swaps and NDFs. The stage (c) in the corporate/bank borrowing along with current account surplus created ruble liquidity when the CBR intervened in the FX market. A consequence of the FX interventions was the increase of excess liquidity which further dampened short-term rates: at some point, 3-month interbank rate moved below 3-month US dollar Libor rate (Chart 10). In the interbank market, the 3-month interbank rate became essentially a ceiling for the implied 3-month NDF rate (Gurvich and others, 2009), while interest rate swap (IRS) rates were close to XCCY-swap rates and to OFZ yields as well (Chart 8$){ }^{3}$

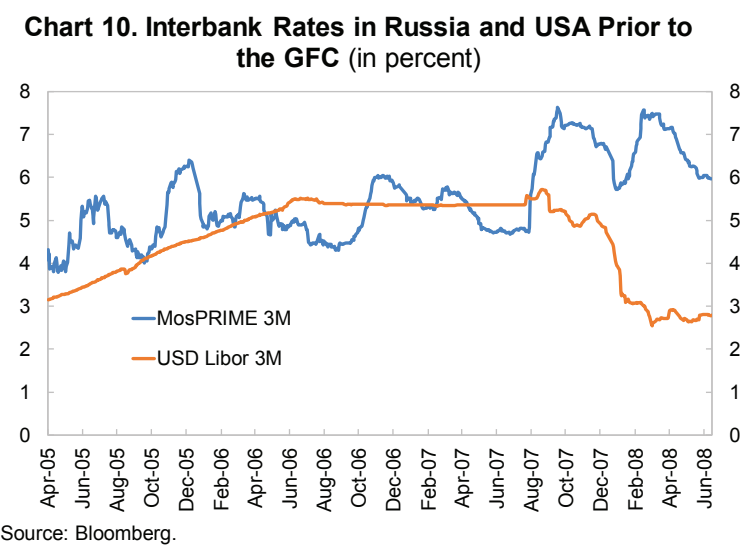

The influence of foreign investors on interest rates prior to the GFC substantially limited the ability of the CBR to control inflation. With the key goal being preventing the appreciation of the ruble, the CBR could not raise the floor of its corridor substantially higher than the level indicated by the XCCY-swap/NDF curve, as such hike would intensify speculative capital inflows.

\footnotetext{
${ }^{3}$ When the GFC hit the global financial markets in the second of 2008, the evaporation of foreign demand for Russian risk broke the CIP link between OFZ, XCCY-swap, and IRS and their rates substantially diverged until the re-emergence of foreign interest in the second half of 2009 (Chart 8).
} 


\section{From 2009 to the summer of 2011}

The activity of the OFZ bond market increased during this period when the MOF had to issue OFZ bonds to finance large budget deficits caused by countercyclical fiscal expansion.

The MOF had taken a balanced approach to enhance the attractiveness of OFZ bonds while avoiding crowding out the private sector. To appeal to a wider set of investors, almost all the newly auctioned bonds were standard fixed-rate bullet bonds (Chart 11), making most of them qualified for GBI-EM indices (Chart 12). The MOF was reluctant to sell bonds at all costs and instead it set the premium of the re-openings to the existing secondary market curve at $5-10$ basis points (with a bit higher premium for debut terms). This practice helped to preserve the stability of the yield curve.

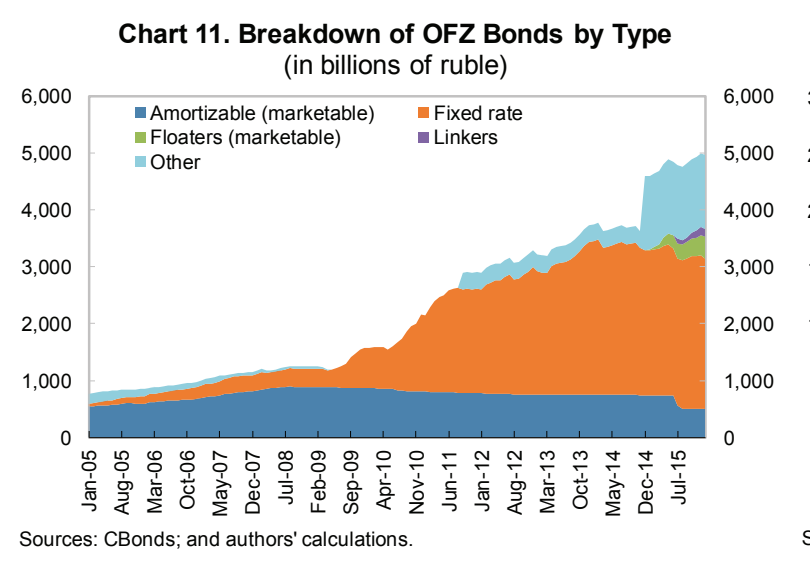

The MOF's prudent approach meant that the receipts from bond issuance alone were not adequate to finance the entire budget deficits. Instead of forcing government-affiliated institutions to absorb additional issuance, the MOF heavily relied on funds accumulated at its accounts (mainly the Reserve Fund) to finance budget deficits (Chart 13). In other words, the buffer role provided by the Reserve Fund allowed the MOF to maintain a healthy issuance policy and minimize the distortion to the OFZ market.
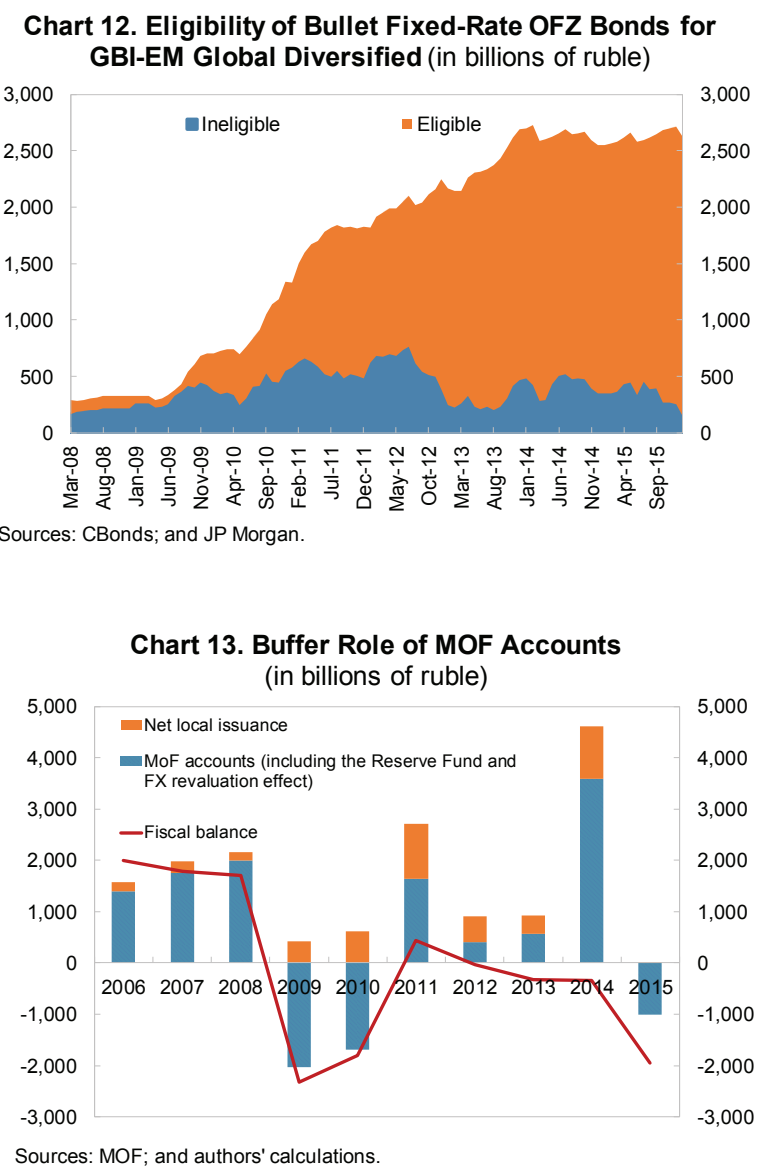

Despite the low premium, private investors, mainly banks, were able to absorb new issuances due to excess liquidity. The tight liquidity related to the GFC started to dissipate in the second quarter of 2009, and the Russian banking system was again awash with excess liquidity between early-2010 and mid-2011, partly due to the recovery in commodity exports (Chart 14). Such excess liquidity drove the overnight interbank rate (MIACR) very close to the CBR deposit rate (floor of the CBR policy rate corridor) (Chart 15). The decline of bank loans to non-financial private sector over mid-2009-mid-2010 - first as a result of a 
reduction in loan supply, then a drop in credit demand (Yudaeva and others, 2009; Deryugina and others, 2015) — also provided additional space for banks to absorb OFZ bonds (Chart 16).
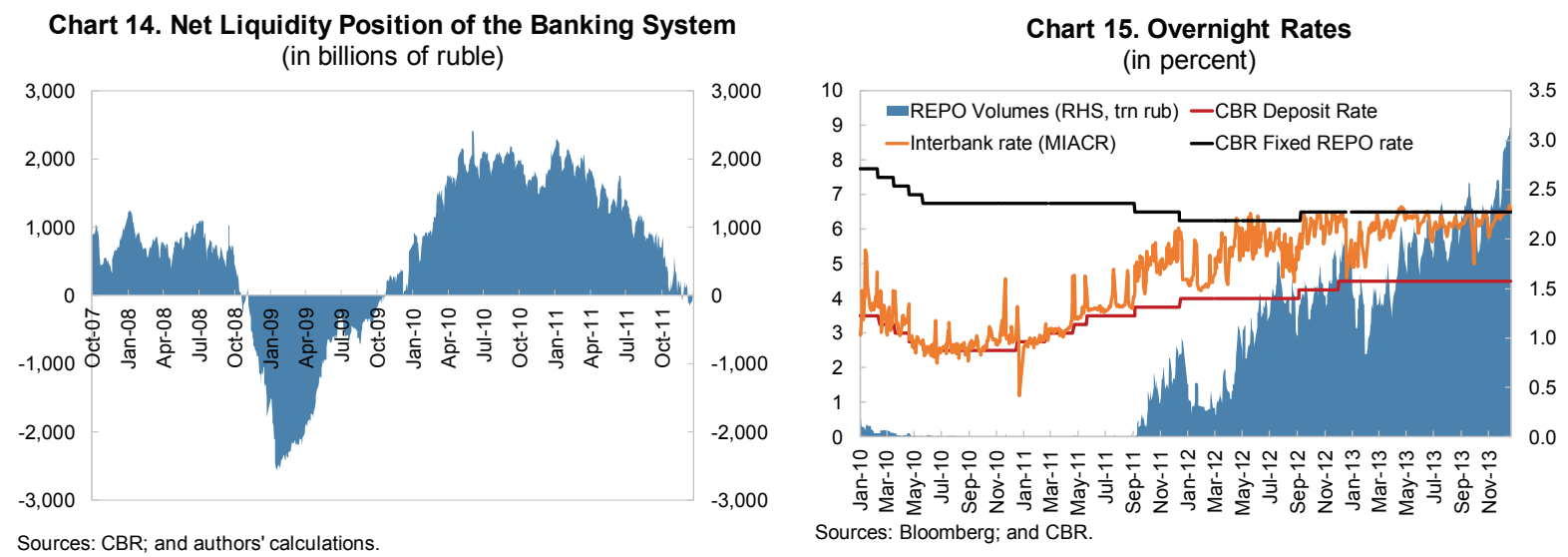

Foreign investors' interest in OFZ bonds recovered after the acute episode of the GFC was over. The stabilization of the foreign exchange market, together with the qualification of new bonds for GBI-EM indices, led to an increase in foreign interest in ruble-denominated fixedincome instruments, which can be observed by the increase in direct foreign ownership (Euromoney, 2012) and the re-convergence of the rates of OFZ, XCCY-swap, and IRS (Chart 8).

Partly due to the uncertainty about the CBR's policy direction, the maturity of OFZ bonds could not be substantially lengthened. In the environment of excess liquidity, the steadily increasing inflation (starting from the summer of 2010), and the potential risk related to "hot

Chart 16. Loans and Bonds Held by Banks (in percent of total assets)

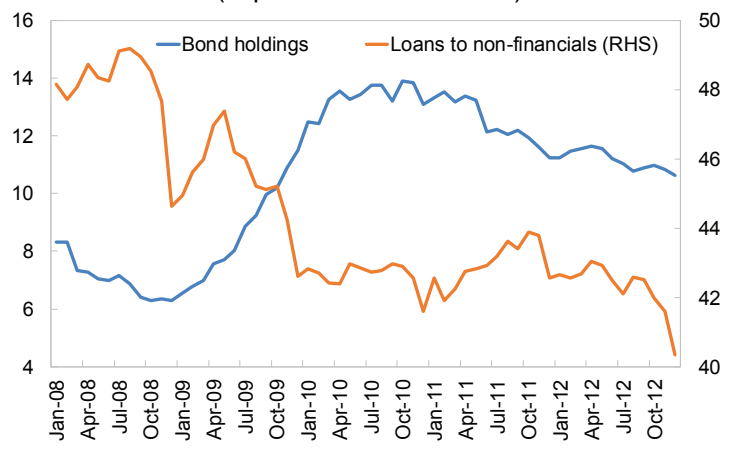

Sources: Haver; and authors' calculations. money" inflows, investors were uncertain about whether the CBR was to increase policy rates. This uncertainty led to their limited interest in investing in longer-term OFZ bonds. Consequently, the MOF was struggling with fulfilling its plan to issue longer-term bonds. The average maturity of auctioned bonds was mostly in the range of 2-4 years, below the average duration of bonds in GBI-EM indices (Charts 17 and 18). 

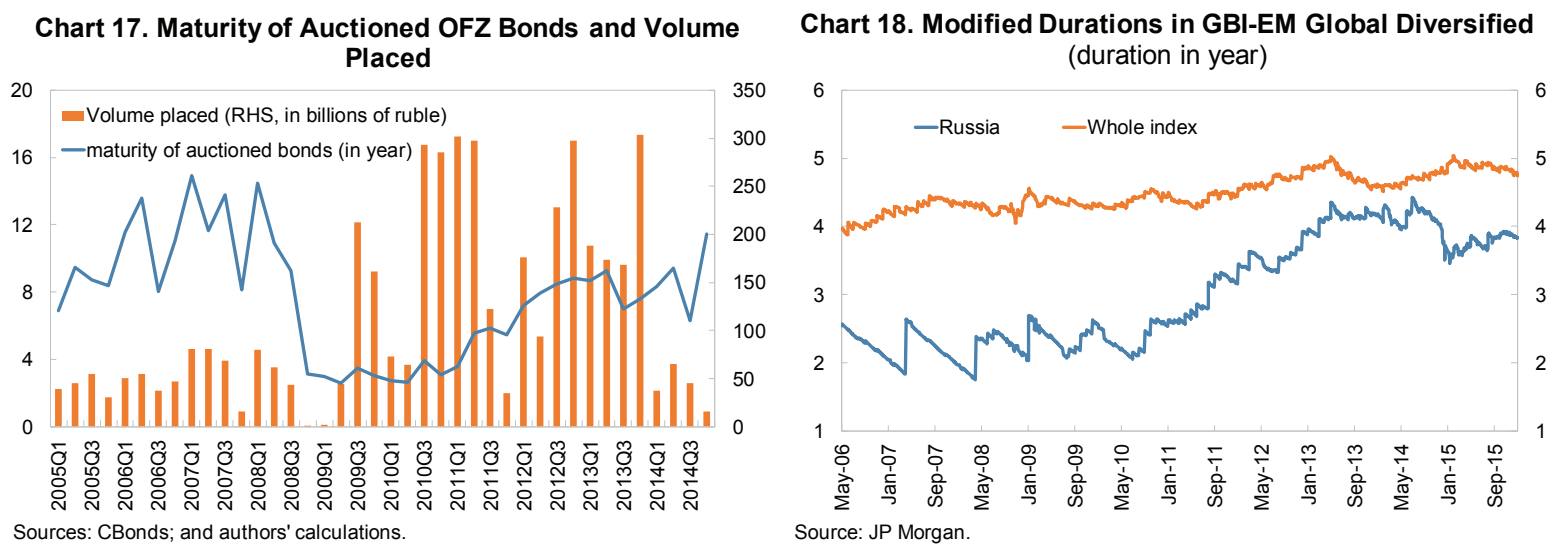

\section{After the summer of 2011}

The banking sector's liquidity position switched to shortage in the summer of 2011. Capital outflows intensified when the turmoil in the euro area triggered a global flight to safety. The CBR's FX intervention to fend off the depreciation pressure drained up ruble liquidity. Also the increase in net government balance at the CBR, a consequence of improved fiscal balance, reduced the supply of ruble liquidity (as the liquidity was transferred to the MOF's account at the CBR).

This switch in liquidity had a positive impact on the development of the OFZ bond market and also helped to improve the CBR's monetary policy transition mechanism. The shortage of liquidity, its likelihood of further intensification, and the favorable regulatory treatment of OFZ bonds in capital and liquidity requirements led banks to reemphasize the role of OFZ bonds in their asset-liability management strategies. Meanwhile, the CBR also took steps to improve its monetary operations to enhance the credibility of its determination in adopting the IT. For example, it relied more on repo auction transactions in managing systemic liquidity (Chart 19), and improved its communication strategies. These changes elevated the importance of OFZ bonds, and improved interbank market's response to changes in policy rates, resulting in a repricing of the whole spectrum of fixedincome and money market instruments. For example, the overnight MIACR started to move closer to the upper boundary of the corridor rather than sticking to the $\mathrm{CBR}$ deposit rate (Chart 15).

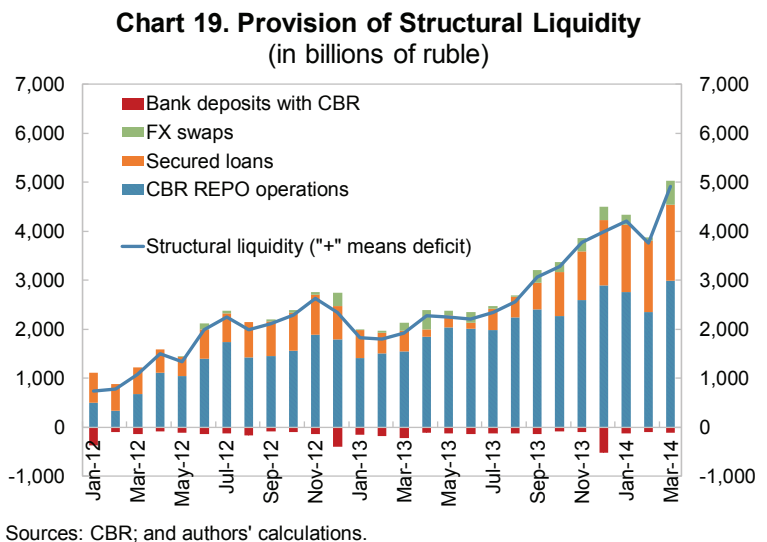

Sources: CBR; and authors' calculations.

Not just the short-term rate, the credibility of the CBR's determination to adopt the IT led to an overhaul of the mechanism of yield curve formation. Because of enhanced credibility, future interest rates started to become linked to the inflation expectations, in contrast to the previously dominated pattern in which future interest rates were influenced by foreign investors' remuneration for bearing currency risk. The slope of the yield curve became 
almost flat at end-2012 (Chart 20), as inflation was expected to decline (Chart 21), driving down the expected future interest rates. This new mechanism allowed long-term macro expectations to influence trading ideas and enabled market analysts to interpret market consensus from transaction data, thus making Russia's sovereign yield curve an important element of macro-financial framework, as the case in countries with developed fixed-income markets.

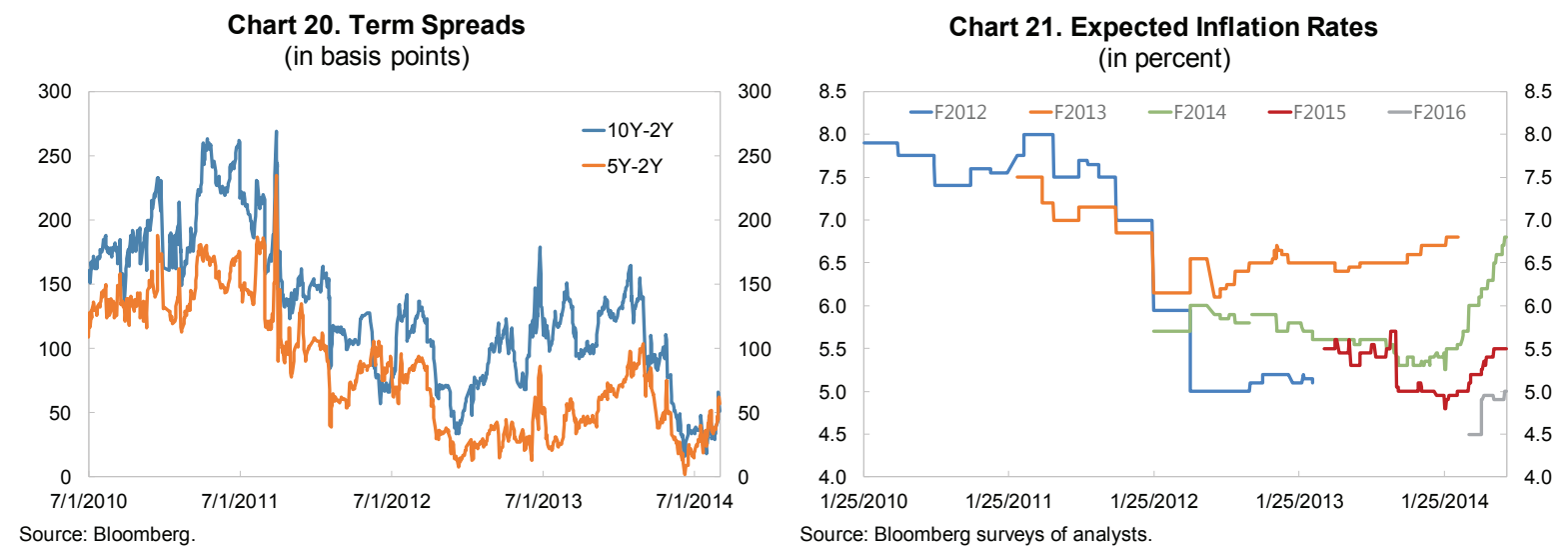

The importance of OFZ bonds was reflected in their high utilization in transactions with the CBR. On the one hand, as a consequence of liquidity shortage, Russia had relatively higher reliance on central bank funding compared to other EMs (Chart 22). On the other hand, Russian banks historically held a low share of bonds on their balance sheets (Chart 23). This imbalance between banks' needs for collateral and their actual holdings led to a high utilization of tradable assets in CBR repo operations. The system-wide utilization ratio reached 50 percent at end2012 (Chart 24). About half of the eligible and tradable collaterals were OFZ bonds.

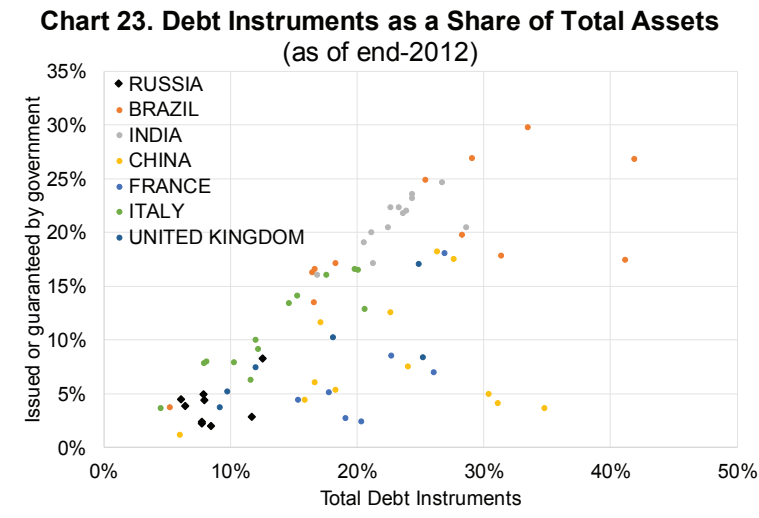

Sources: SNL; and authors' calculations.

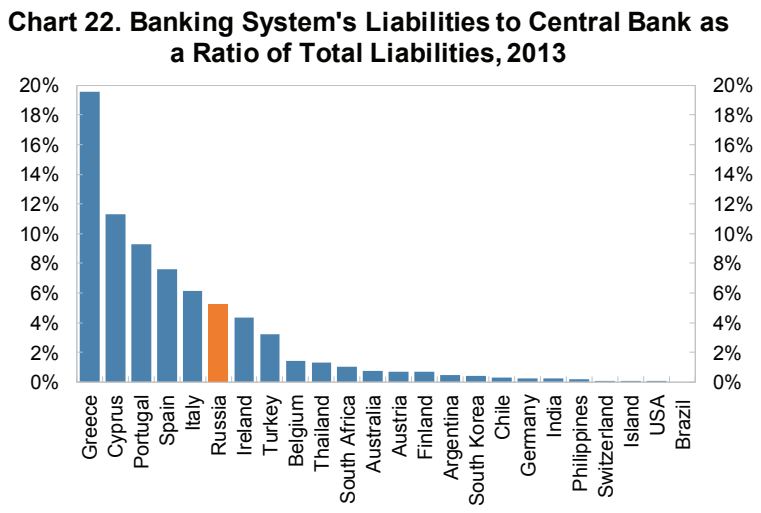

Sources: CBR; and IMF.

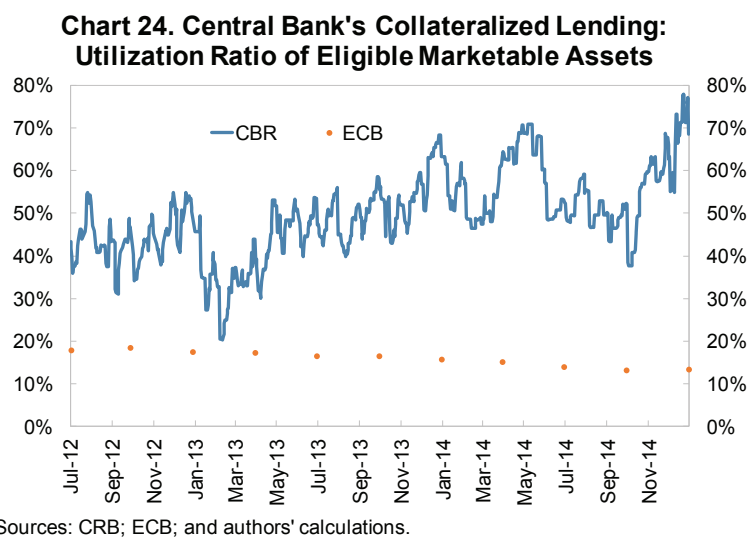


This high utilization constrained the secondary market activity. As high utilization resulted in a large share of OFZ bonds being encumbered as collaterals (e.g., Sberbank, Chart 25), the limited amount of tradable OFZ bonds constrained the ability of local banks to actively participate in the secondary market.

In this environment foreign investors became a main provider of liquidity since the beginning of 2012. As foreign purchase exceeded the net issuance of OFZ bonds, local ownership declined in 2012 (Chart 26). Given that the new issuance was made predominately in the form of fixed-rate bullet bonds and that foreign investors generally had no interest in the previously issued amortizable bonds, foreign participation in the actively traded bonds was estimated at up to 50 percent and even higher in the on-the-run segment. ${ }^{4}$
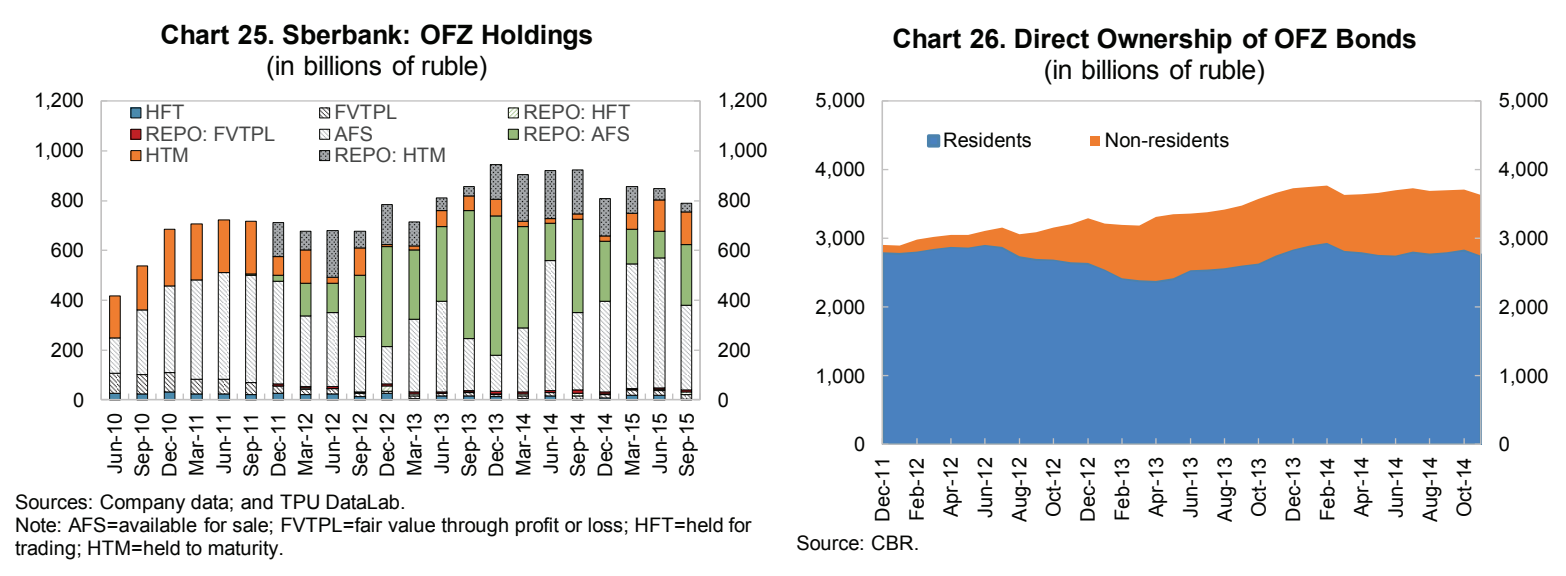

The role of foreign investors in the longer-end of the yield curve was particularly important. In February 2012, the MOF pointed out that the sizable foreign demand for longer-term bonds allowed it to successfully re-tap the market with a 10-year bond and place a debut 15-year bond (Reuters, 2012). This ability to extend duration was in contrast to what was observed before the summer of 2011. It was estimated that foreign investors held up to 50-60 percent of the most actively traded bonds in the segment of 7-9 years (BCS, 2014). Given that the share of banks in those bonds were either small or utilized in the CBR repo operations (BCS, 2014) and that the remaining investors were mostly buy-and-hold investors (e.g., the SPFR), the secondary market trading of those bonds was dominated by foreign investors.

\section{B. Foreign Exposure to the OFZ Risk through Proxies}

Besides purchasing and holding domestic sovereign bonds, foreign investors can use proxy instruments to gain similar exposure. Using proxy instruments helps them to circumvent legal, regulatory, and infrastructure barriers, and sometimes to avoid taxes. An understanding of foreign position in proxy instruments is important for countries that have not yet liberalized their domestic trading and settlement infrastructures, as foreign investors could

\footnotetext{
${ }^{4}$ Based on daily analysts' notes after auctions of OFZ bonds.
} 
use proxies to express their views on LCY bonds, and their risk-on or risk-off behavior, often spilling over to domestic financial markets, could potentially catch the domestic markets and authorities by surprise.

In the case of OFZ bonds, these proxy instruments can be grouped into two types. One is financial derivatives that synthesize the exposure to OFZ bonds. The other is rubledenominated Eurobonds and domestic non-OFZ bonds with similar risk profile.

\section{Total return swaps (TRSs) and credit linked notes (CLNs) backed by OFZ bonds}

TRSs and CLNs are credit derivatives normally contracted between a global investment bank (GIB) and a foreign investor, the ultimate holder, which gets cash flows from the underlying cash OFZ bonds, though the timing, costs, and currency of payments may vary depending on specifics of a particular deal. The legal owner of the bonds may be a Russian subsidiary of the GIB (GIB-sub), hence, in the official publication, the owner would be classified as "residents" instead of "foreign investors". TRSs and CLNs are attractive for investors who are either reluctant or not allowed by their mandates to open an account in a local clearing and settlement infrastructure. In some cases, investors use these instruments to test the water or time the markets before switching later to cash bonds after the market is liberalized (Chart 27).

While it is possible to find some information about the volume of CLNs, information about TRSs is difficult to gather. A rough approximation is the OFZ bond position of GIB-subs. However, their books also include sizable positions for proprietary trading and interest raterisk hedging. In addition, some sellers of proxies also synthesize the exposure instead of holding the underlying cash bonds.

TRSs and CLNs carry sovereign default risk, counterparty risk, and sometimes currency risk depending on investors' accounting currency. To reduce counterparty risk, investors sometimes have multiple TRSs and CLNs with different GIB counterparties backed by the same underlying OFZ bonds. As bespoke derivatives, TRSs and CLNs do not have any market liquidity.

\section{XCCY-swaps and NDFs}

XCCY-swaps and NDFs are offshore OTC derivatives that could provide foreign investors access to cash OFZ bond risks. For instance, the large volume of XCCY-swap market allowed investors to obtain sizable positions prior to the liberalization. However, most of the liquidity was concentrated in the medium-term (Chart 28), and the market had a very specific core investor base including large Russian corporates and banks that use XCCY-swaps mostly to alter their funding currency. Still, it was easier to implement arbitrage strategies on OTC derivatives market rather than in the cash bond market before the liberalization.

Despite their popularity even prior to the GFC, they carry limits for investors wishing to get exposure to ruble yields. First, as OTC derivatives they carry various risks such as counterparty risk, basis risk, liquidity risk, and sometimes currency risk. Though they are not subject to sovereign default risk, the valuation of these instruments could be affected by a sovereign 
credit event. Second, the size of the XCCY-swap market hinges to a large extent on the need of Russian corporates to hedge their FX risks, which may not remain strong in the long term. Third, price discovery is more difficult than in the cash bond market, as XCCY-swaps will gradually mature to fractional terms while the active quotation has to be done at integer terms. Fourth, the degree of data dissemination and transparency of the cash bond market is typically higher than those of the XCCY-swap market.
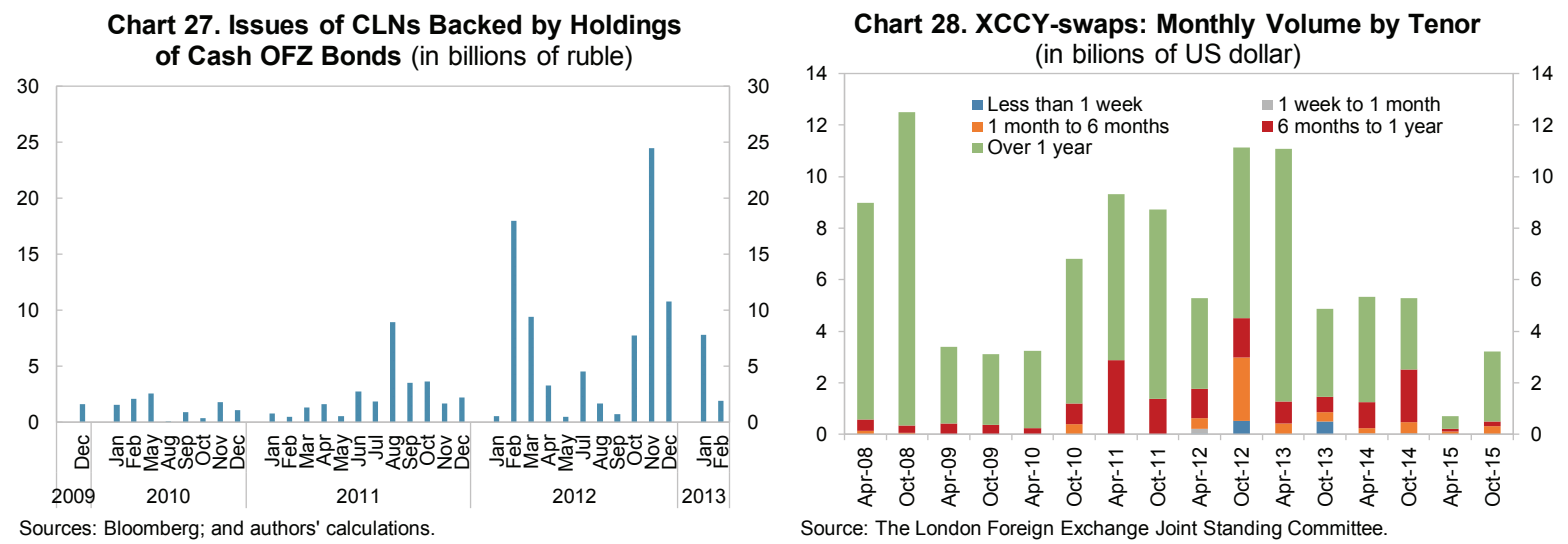

\section{Ruble-denominated sovereign Eurobonds}

As a response to global demand for LCY government bonds, the MOF had placed rubledenominated Eurobond to facilitate foreign access to ruble-denominated securities. In Feb 2011, the MOF placed RUB40 billion (US\$1.37 billion) of a debut 7-year ruble-denominated Eurobond. In May 2011, it placed additional RUB50 billion (US\$1.78 billion) of the same bond. Once it became clear in the second half of 2011 that the liberalization of the OFZ bond market would take place, it stopped placing ruble-denominated Eurobonds.

\section{Domestically issued corporate bonds or ruble-denominated corporate Eurobonds of high credit quality or quasi-sovereign borrowers}

These bonds provide higher returns than government bonds with comparable credit quality and decent secondary market liquidity. The credit premium of holding domestically issued corporate bonds may be able to cover the cost of accessing local infrastructure. However, due to their short duration, they may only be a substitute for short- and medium-term sovereign bonds. In addition, their attractiveness to investors is constrained by the operational costs of monitoring credit quality of each corporate issuer. The importance of Russian domestic corporate bonds in foreign investors' portfolios has declined since mid-2012 (Chart 29).

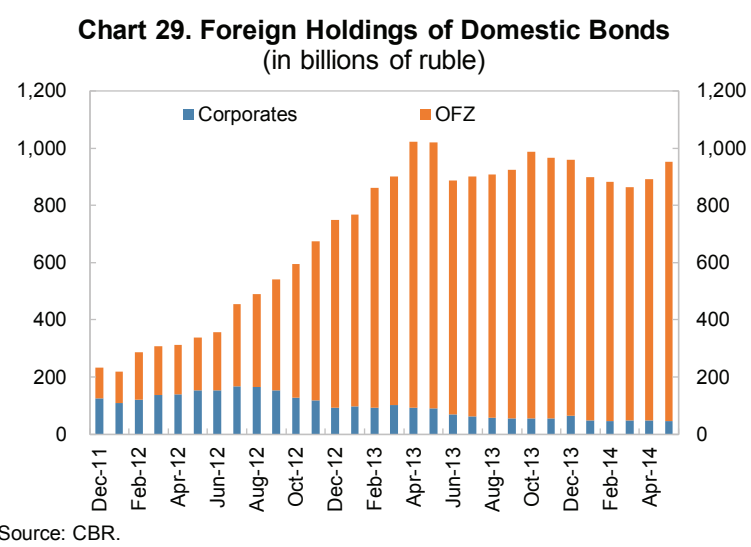


Information about foreign participation in corporate Eurobonds is limited, as the international central securities depositories (ICSDs) usually do not disclose the composition of holders of Eurobonds, and there is no regular publication of investor composition of domestically issued corporate bonds.

\section{Supranational and development banks' (SN\&DB) ruble-denominated Eurobonds}

Prior to 2011, SN\&DB bonds dominated the stock of ruble-denominated Eurobonds. However, since 2011, their share has been eroded by the large issuance of rubledenominated corporate and sovereign Eurobonds (Chart 30). Their short remaining time to maturity did not appeal to investors who prefer longer-term exposures. In addition, their liquidity was constrained by the small issuance size (mostly less than RUB5 billion compared to the corporate issuance of RUB10-20 billion), and, in some cases, by their only being issued to a narrowly targeted set of investors.

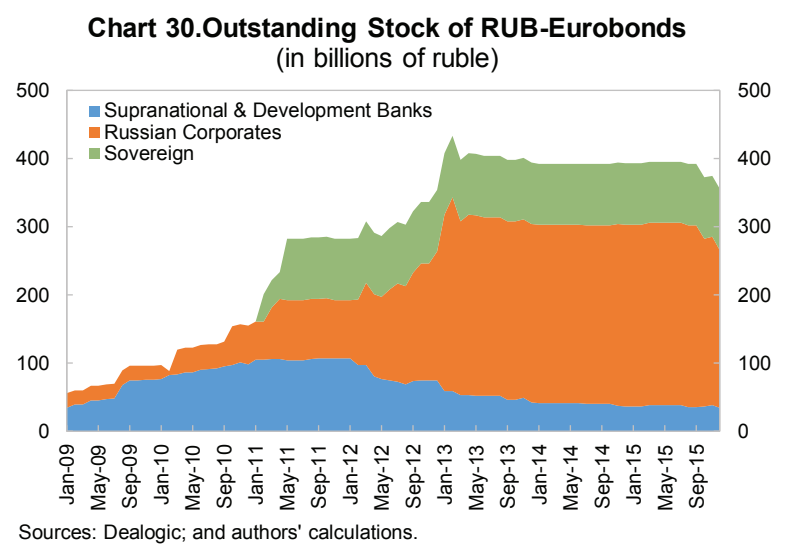

In summary, due to the existence of the above mentioned instruments, the data published by the CBR on foreign ownership of OFZ bonds may underestimate the ultimate foreign exposure to OFZ bond risks. Public data on foreign ownership, compiled based on reporting from custodians who collect information on bond holdings by residency, would exclude positions of GIB-subs built on behalf of foreign investors. Local custodians do not collect information about foreign ownership of ruble-denominated Eurobonds while the market consensus put the share of foreign ownership at 60-80 percent (Gazprobank, 2014). The amount of interest rate and foreign exchange derivatives constructed for foreign investors to get the exposure to OFZ bond risk remains unknown.

Such underestimation could be confirmed by asset allocations of funds that track flagship indices. Before the liberalization, the amount of foreign holdings of OFZ bonds, published by the CBR, were less than the assets under management (AUM) of funds that tracked GBI-EM indices (Chart 31). The JPMorgan client survey indicated that benchmark-driven funds were moderately underweight OFZ bonds before and at end-June 2012; neutral at end-July 2012; and overweight at end-August 2012. This survey implies that at end-July 2012 the total amount allocated to Russia in these benchmark-driven funds should be more or less equal to the AUM-adjusted allocation to the Russian weight in GBI-EM indices (corresponding to about RUB500 billion). Since the published amount of foreign holdings of cash bonds at end-July 2012, at RUB288 billion, was much smaller than

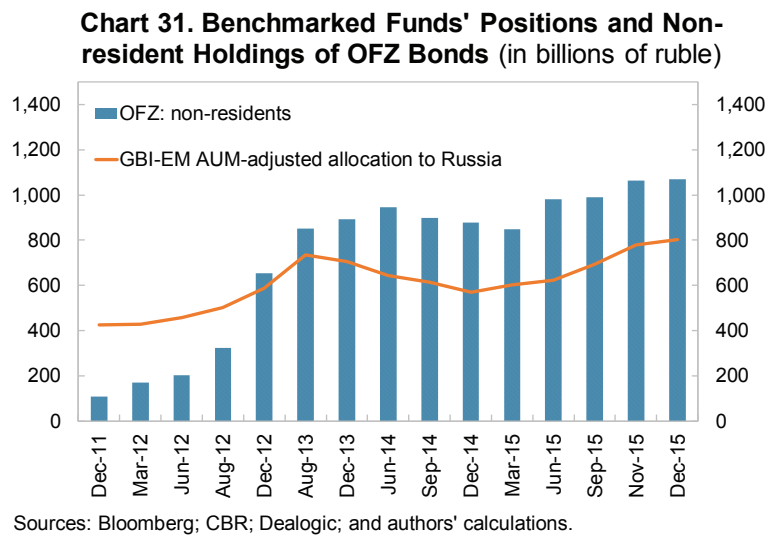


RUB500 billion, it can be derived that proxy instruments were involved. Based on this information, it can be estimated that before end-2012, about 40-60 percent of the overall benchmark-driven funds' exposure to OFZ bonds was obtained through proxy instruments.

Information provided by individual funds also confirms the roles of proxy instruments. For example, the Invesco Emerging Local Currencies Debt Fund, which tracks the GBI-EM Global Diversified Index (the most popular index among the family of GBI-EM indices), mainly relied on corporate Eurobonds to get exposure to Russia before 2013 (Chart 32). The Ashmore Emerging Markets Local Currency Bond Fund, which also tracks the GBI-EM Global Diversified Index, relied on TRSs on OFZ bonds to obtain the exposure before early 2012 (Chart 33).

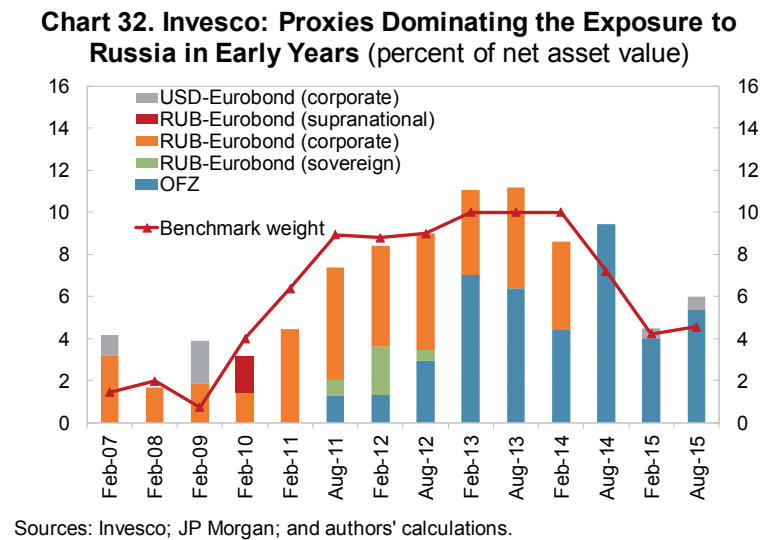

Sources: Invesco; JP Morgan; and authors' calculations.

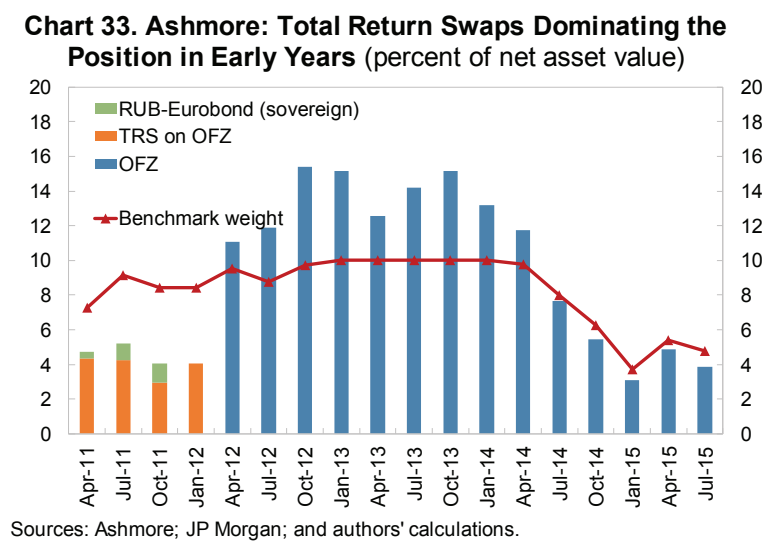

\section{The Process of Liberalization}

The collapse of the Soviet Union released a tremendous amount of entrepreneurial spirit. Despite (or because of) a lack of proper financial regulations, the number of financial intermediaries mushroomed in the early 1990s. For instance, the number of stock and commodity exchanges in Russia was probably more than in any other country in the world. Similarly, the number of banks exploded in the early 1990s, as well as the number of brokers, depositories, and registrars (Charts 34 and 35).

However, most of these institutions did not last long. First of all, the introduction of stricter licensing restrictions removed the least sound players from the market. Second, many were unable to survive the multiple shocks throughout 1990s (most notably the GKO default in 1998). Third, natural competition forced most of the players to either exit from the market or be absorbed by the larger or more efficient players.

Even though natural forces gradually led to consolidation and integration, a complex and fragmented local trading and settlement infrastructures lasted longer than acceptable for core groups of investors. The improvement might be achieved in two ways. One is to seek a more pronounced specialization in each particular area of financial intermediation by a small group of leading institutions. The other way is to seek a consolidation of different functions in a centralized entity (or a group of related entities), in particular through the consolidation of exchange trading and settlement functions. 

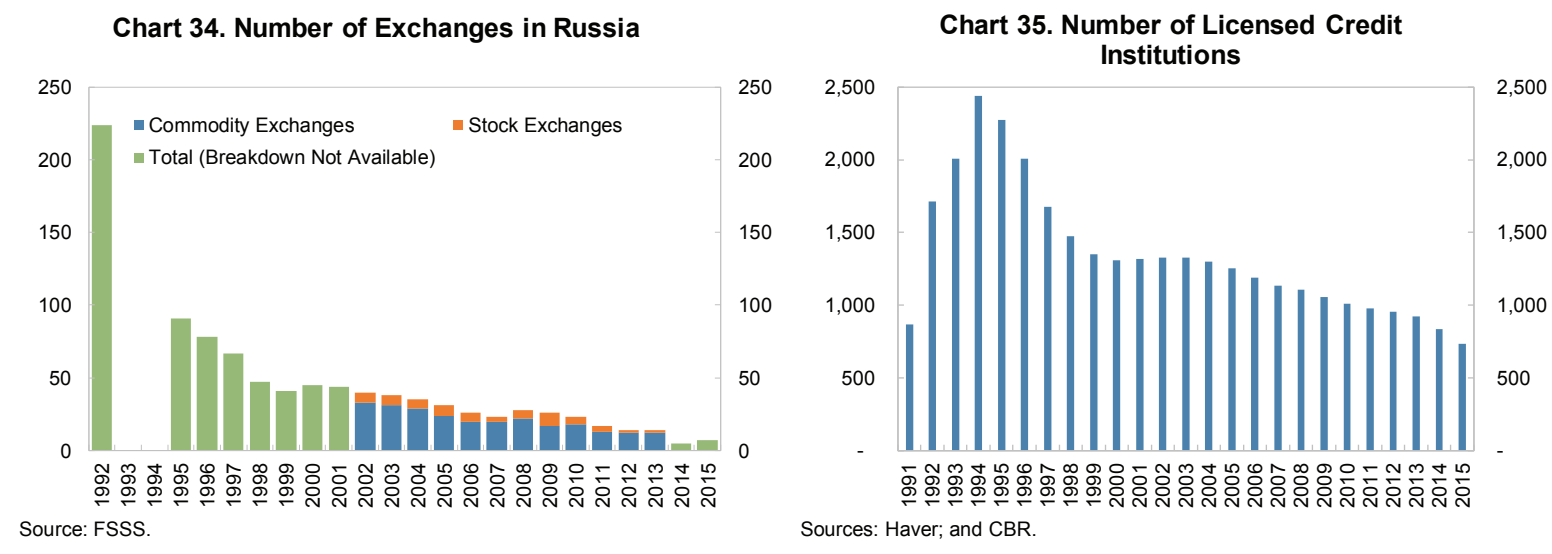

The consolidation of exchanges, if taking place, would most likely involve two dominant exchanges: the Moscow Interbank Currency Exchange (MICEX) and the Russian Trading System (RTS). MICEX was a state-affiliated exchange, established in 1992 for foreign currency trading, and later it developed a platform for state debt (GKO) trading, and gradually expanded into other areas such as corporate fixed-income and stocks. It was perceived by its founders as the best candidate for the center of the long-term consolidation of trading and settlement infrastructures. However, the founders had never imposed any administrative measures to establish its leadership. The RTS was established by a group of influential private market operators with its strategy defined by the needs of its founders and focused on organic expansion. Both had separate settlement depositories: MICEX had the National Depositary Center (NDC); and the RTS had the Depository and Clearing Company (DCC).

In line with the above-mentioned two ways of improvements, there were two options to unify MICEX and the RTS. One is to perform a deep integration of their internal processes while keeping them as separate entities. The other is to merge them into one entity. The first option raised questions about how to practically assign a special legal "integrating" title to two entities that were actively competing in some segments. This left with the second option. A few steps of integration were done in early and mid-2000. For instance, for the settlement parts of the exchanges, inspired by the Euroclear-Cedel bridge, a "depository bridge" between the NDC and DCC was established in 1999, and in 2004, NDC purchased nearly 37 percent of DCC shares.

Besides the integration of settlement infrastructures, changes in other legal and regulatory elements of the financial system were required to modernize the financial intermediation in the mid-2000s. Such changes included the introduction of central counterparty, security lending, establishing complete Delivery-versus-Payment (DVP) and $\mathrm{T}+\mathrm{X}$ (e.g., $\mathrm{T}+3$ and $\mathrm{T}+2$ ) settlement modes for all types of cash securities, and different post-trade services. Market practitioners highlighted that without these elements Russia's domestic financial infrastructure cannot compete with foreign trading hubs and consequently Russia would have to either allow the liquidity to move offshore or artificially keep it in Russia at the expense of market efficiency. 
These required changes dovetailed with the ambitions of the Russian government to create a global financial center in Moscow. In 2008, the government signed "the conception of longterm economic development of Russia until 2020" which aspired to create the "infrastructure for the International Financial Center (IFC) in Moscow".

The first big move by the government was merging MICEX and the RTS. In September 2011, the RTS was acquired by MICEX and the two were merged into an entity, the Moscow Exchange (MOEX). The DCC transferred its operations to the NDC while the latter was rebranded as the National Settlement Depository (NSD). MOEX's shares became publicly traded, a step planned in the initial letter of intent for the merge (Forbes, 2011).

The restriction to OTC trading and the mandatory requirement for the separation of accounts were removed in the first quarter of 2012. Before the removal, despite the consolidation of infrastructures, the infrastructure of the OFZ bond market was isolated even domestically. OTC trading of OFZ bonds was not allowed and all the transactions, including deals negotiated over the counter, had to be concluded in the infrastructure of MOEX. Within MOEX, the accounts for trading OFZ bonds were required to be separated from those for other instruments, complicating the process of asset reallocation for portfolio managers that had other instruments.

The NSD became qualified as a central securities depository (CSD) and the concept of the foreign nominee was introduced in November 2012 (Box 1). Before that time, foreign investors' access to the domestic market was low. In the absence of the concept of foreign nominee, if an ICSD opened an account at a depository in Russia, this ICSD would be treated as the legal holder of assets instead of being just a nominee for them. Investors and analysts frequently expressed opinions that in a credit event, the ICSD would be forced to discriminate against some of its clients, because, as the only legal holder, it is impossible to represent positions of different types of its clients who may have contradictory approaches to restructuring. In some cases, mandates of some investment funds do not allow them to keep securities in domestic clearing and settlement infrastructure. In addition, typically, foreign investors are accustomed to working with one custodian to access all the markets, while it is the job of the custodian to establish necessary depository chains, which frequently requires the operations of ICSDs (most notably, Euroclear and Clearstream) in the domestic market.

These reforms were carried forward despite the pressure arising from fear of shifting liquidity abroad. Such fear was mainly on the equity market given its large turnover compared to all the combined fixed-income instruments (Chart 36). The size of the offshore secondary turnover of Russian stocks had been at least half the size of domestic turnover and for some periods even exceeded domestic turnover (Noel and others, 2006, and NAUFOR, 2014). In domestic markets, foreign investors represented 30-50 percent of the secondary market turnover of equities, a share similar to individual investors. There was a concern that 
if the concept of foreign nominee were introduced, ICSDs would be allowed to settle secondary market transactions and consequently all the liquidity and price discovery would be shifted to foreign trading hubs. Some had concerns that opening domestic markets to ICSDs could divert revenues to ICSDs at the expense of organic development of domestic clearing and settlement infrastructure. The overprotection of domestic equity infrastructure due to these concerns also affected the access of foreign investors to the OFZ bond market.

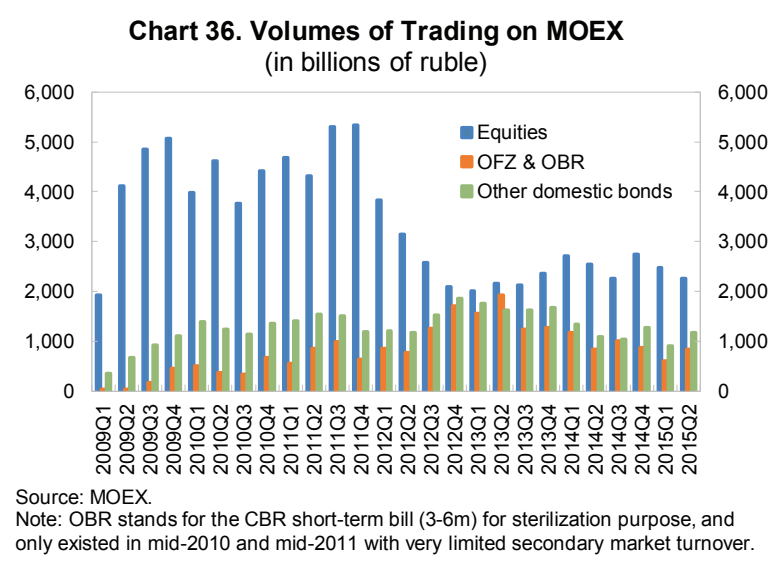

Box 1: Establishment of the CSD and Introduction of Foreign Nominee

Before the establishment of the CSD, foreign investors had the view that the Russian law did not guarantee that an account at the NSD would be equivalent to an account at the registrar. As a result, investors or their global custodians had to bypass the NSD to directly deal with the registrar, which was inefficient and costly. This view was based on the fact that the legal status of the NSD was not qualified as an "eligible securities depository" under the Rule $17 \mathrm{f}-7$ of the U.S. Investment Company Act (https://www.nsd.ru/en/about/interact/rule 17f 7/). In principle, the Rule $17 \mathrm{f}-7 \mathrm{implies}$ that the fund manager makes his own judgement on whether a particular settlement infrastructure complies with the rule. In practice, this judgement is made with the assistance of the investor's global custodians. Despite the NSD's effort to prove its qualification, the Association of Global Custodians (AGC) had a couple of concerns. First, the NSD did not have a legislation-based CSD mandate, i.e., it was not officially called a CSD by the government. Second, the NSD did not have a CSD license, i.e., it did not follow any formal set of rules keeping its activity within some boundaries. Finally, the NSD had not proved that keeping accounts at the NSD is legally as safe as the registrar of a stock. These concerns meant that the only way for Russia to comply with the rule was to officially create a legal concept of the "Central Securities Depository", empower its records to have higher priority than the registrar's records (with a few exceptions), and assign the status of CSD to the NSD.

On December 7, 2011 the law “On the Central Securities Depository" was signed and came into force on January 1, 2013. The status of the Central Securities Depository was assigned to the NSD on November 6 2012, making it as the only CSD in Russia (even though the Rule $17 \mathrm{f}-7$ does not explicitly require the uniqueness of CSD in one country).

Along with the law on the "Central Securities Depository", a "satellite law" introduced the foreign nominee concept, which allows ICSDs and national CSDs to open nominee account at the NSD, while the satellite law gives global custodians an option to open accounts at ICSDs; the global custodians are not allowed to open nominee accounts at the NSD. 
Despite these concerns, the government pushed ahead. The MOF's voice in liberalization became louder, as its borrowing needs increased since 2009 and the high global demand for EM LCY bonds after the GFC could provide a source of funding. The government removed impediments and made the infrastructure in Russia one of the most convenient among EM LCY government bond markets. In particular, starting from February 7, 2013, Euroclear was fully capable of performing post-trade processing of OTC OFZ bond transactions in the liberalized infrastructure. One year later, foreign investors' access to stock and corporate bond markets was liberalized.

\section{MARKets AdAPting to The Liberalization}

Before the completion of liberalization, market participants were adjusting their mid-term view on the OFZ bond market in anticipation of liberalization-driven regulatory changes. Since late-2011, when it became clear that liberalization would take place, trading ideas based on the expectation of lower OFZ yields driven by potential foreign inflows were among the most cited by analysts (Credit Suisse, 2012). The logic goes as follows. As of end2011, foreign holdings of cash OFZ bonds amounted to RUB107 billion, accounting for 3.7 percent of the total outstanding stock (Chart 37) or 5.9 percent of the stock of fixedrate bullet bonds. Reaching 15-20 percent of ownership, typical in other EMs, would imply an inflow of RUB400-600 billion.

Benchmark-driven funds alone could contribute to about RUB300 billion additional holdings if the full amount were allocated based on Russia's weight in GBI-EM indices (about 9 percent) and the total AUM Chart 37. Holders of OFZ Bonds at end-2011 benchmarked to indices as of end-2011 (about US\$150 billion).

This was indeed what happened. Direct foreign holdings of OFZ bonds increased fivefold in 2012 alone, and their share increased to 20 percent at end-2012 (Chart 38). Some of the increase was due to "search for yield" among ample global liquidity, as other EM LCY government bonds had also experienced a large increase in foreign ownership, however, the increase in the case of Russia stood out. Some of these positions were first purchased in the non-liberalized infrastructure, and then gradually transferred into accounts at ICSDs (Chart 39).

The introduction of ICSDs allowed foreign investors to switch from proxy instruments to direct holding: the issuance of CLNs backed by cash holdings of OFZ bonds virtually disappeared after March 2013 (Chart 27) and the liquidity of XCCY-swaps has been overtaken by that of OFZ bonds since late 2012 (Chart 40).

Market liquidity improved. According to JPMorgan's estimations, the bid-ask spread halved to 5 basis points in 2013, and the average trading size increased from RUB20 million in 2011 to RUB50 million in 2012 and doubled to RUB100 million in 2013. In addition, the frequency of transactions in OTC markets increased after ICSDs started to operate in the 
OFZ bond market, as investors could settle trades via ICSDs without involving the MOEX (Chart 41).
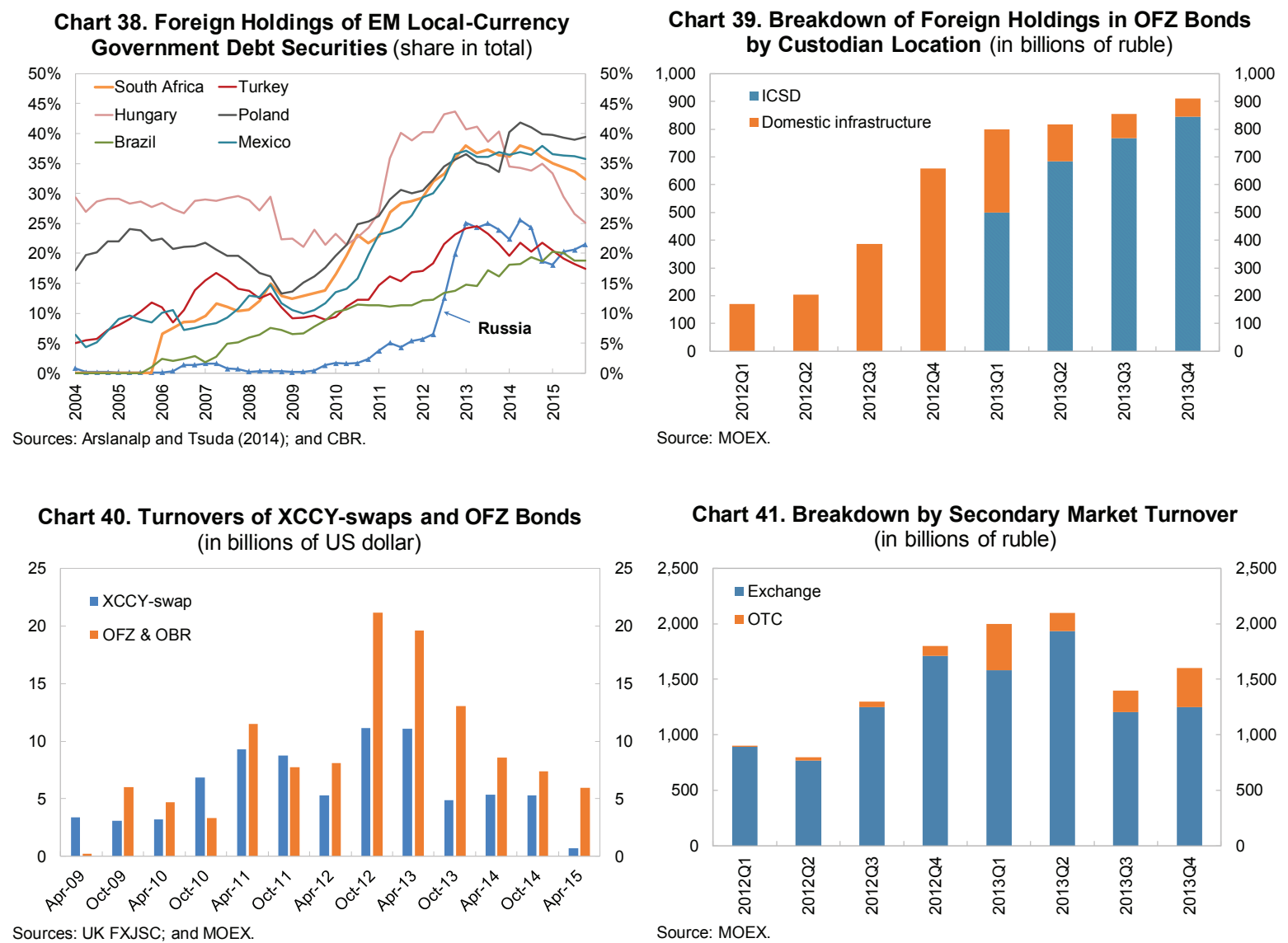

The spread between offshore and onshore instruments tightened along with the progress in liberalization. As such spread roughly measures the total costs of accessing local market instruments (such as the costs of domestic brokerage, depository fees, transaction fees, and domestic legal risks), it is expected to tighten as liberalization moves forward. This tightening took place in Russia: the yield of a ruble-denominated government Eurobond (maturity-March 10, 2018, coupon-7.85 percent) and the yield of an OFZ bond with similar maturity (maturityMarch 15, 2018, coupon-7.5 percent)

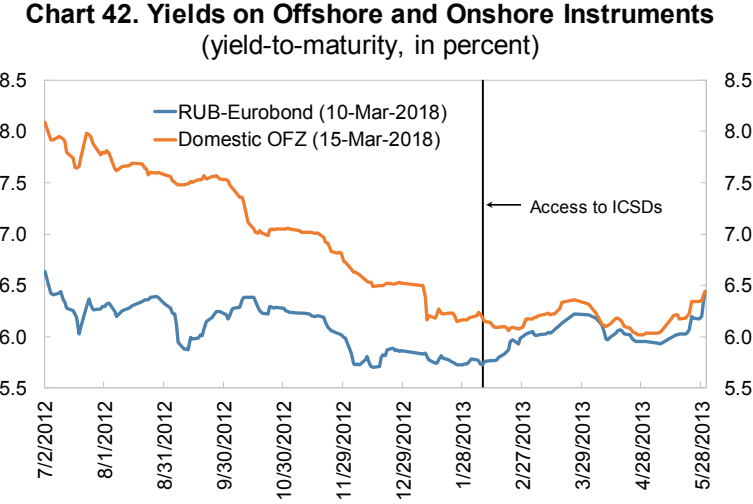

Source: Bloomberg converged as the market become liberalized (Chart 42).

What is behind the tighter spread is the enhanced process for price discovery. Removing infrastructure and legal impediments for foreign access allowed the OFZ bond market to accommodate different types of risk-takers. Foreign investors with ruble-denominated 
holdings typically carry FX, interest rate, and credit risks. Any change in their perception on any one of the three risks could trigger market reaction, especially if there are no other investors to absorb that risk. The risk profile of domestic investors of OFZ bonds is different. OFZ bonds carry no FX risk (as ruble is the domestic currency) with credit risk being one of the lowest among domestic fixed-income instruments. As to interest rate risk, domestic banks are exposed to such risk, but usually they do not sell a substantial position in one-direction market, as any such sale would cause a sizable unrealized loss in their unsold portion of OFZ holdings. The dynamics of OFZ bond yields and offshore Russia yields during the 2008-09 GFC have demonstrated the overreaction of offshore investors relative to domestic investors (Chart 8). The consolidation of the investor base following the liberalization has allowed domestic investors to absorb selling pressures from foreign investors in the event of risk-off and allowed foreign investors to provide additional liquidity when the space and ability of domestic investors are limited, making the OFZ bond market more resilient to various shocks.

Besides improved price discovery, large inflows of foreign investment in 2012H1-2013H1 had significantly altered the structure of dominant market markers in the OFZ bond market. When foreign investment funds execute their trades through global financial institutions, in particular global prime brokers, the order flow ultimately reaches local desks of those institutions, which in the case of Russia are the GIB-subs. Despite their small total assets or security portfolios compared to domestic giants (such as Sberbank and VTB), they have a valuable franchise in global brokerage and a wide international network of clients. As we can see, the share of GIB-subs in the combined turnover of top-50 operators of the OFZ bond market increased from 25-30 percent to 55-60 percent in 2012 H1-2013H1, and the rankings of GIB-subs surpassed most local financial institutions in 2013 (Charts 43 and 44). Given their being the core elements of the foreign investors' execution in the OFZ bond market, the actual order flow coming through them was substantially larger than any of the purely domestic institutions could generate for their own needs or for their domestic clients (especially given the low demand for OFZ bonds outside of the banking sector) (Charts 45 and 46).

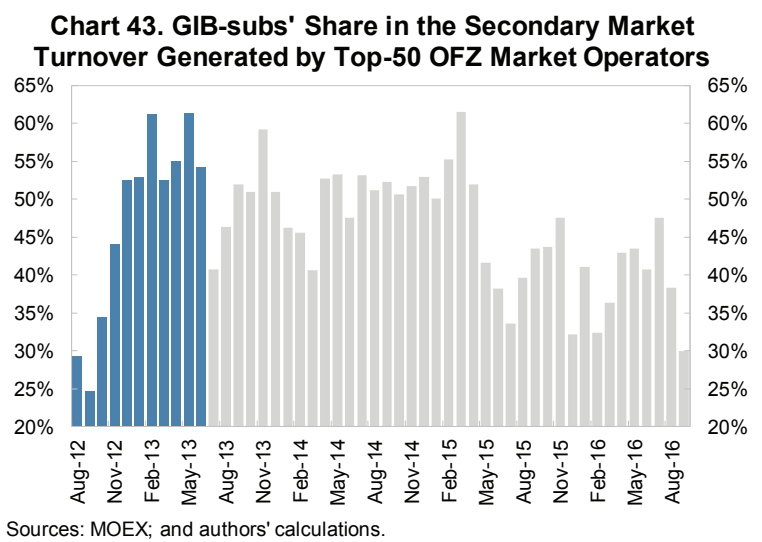

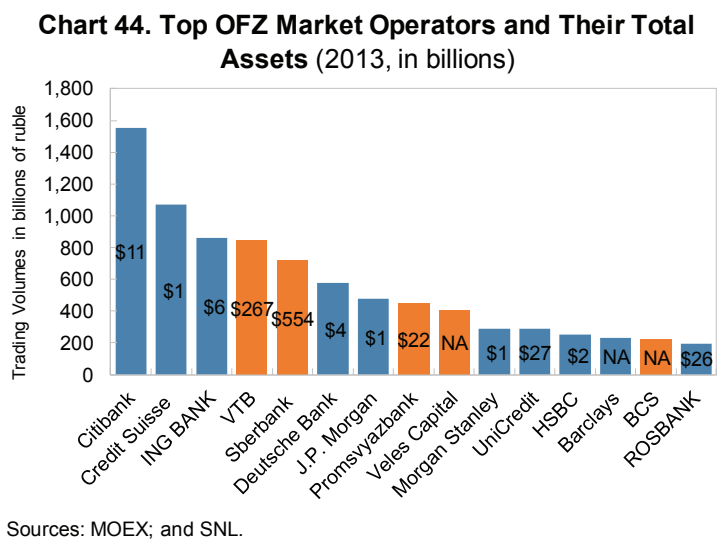



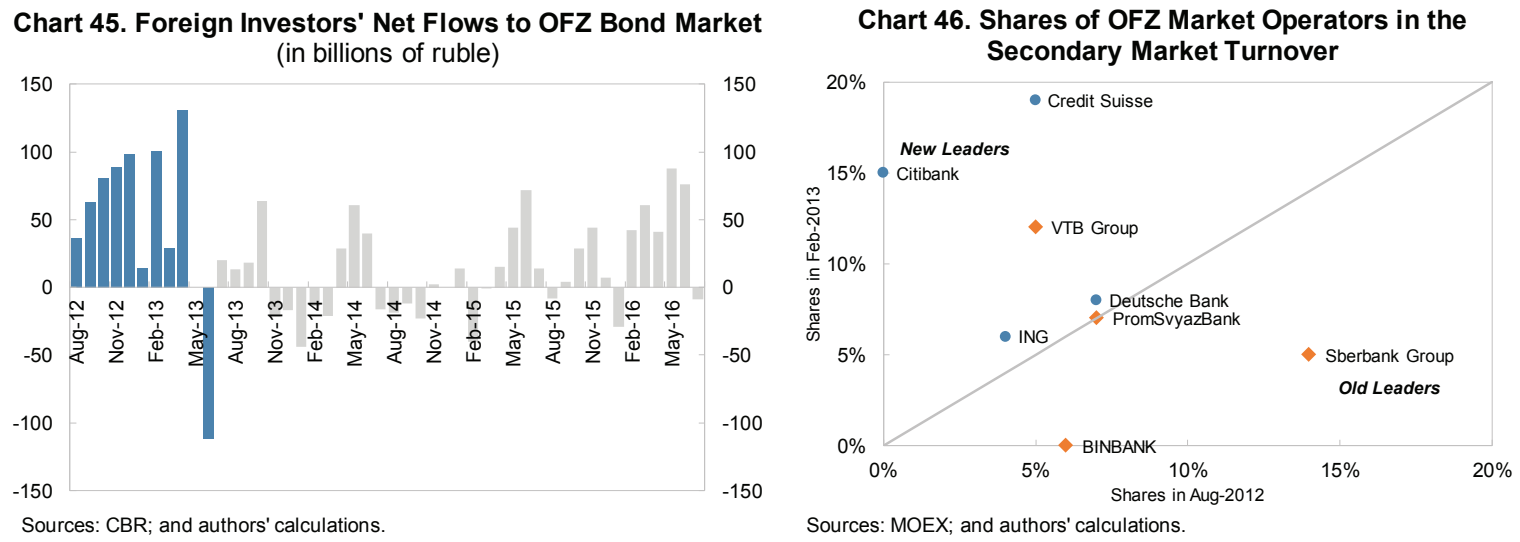

GIB-subs were preemptive in positioning themselves for the liberalization of the OFZ bond market. In 2012, expecting foreign portfolio inflows, some of them rapidly increased their holdings to bet on the expected yield compression or to form cash OFZ bond positions to be employed as underlying assets for CLNs and TRSs issued by their head-offices (Chart 47). In contrast, the position of domestic banks showed little reaction to the expected foreign inflows (Chart 48).
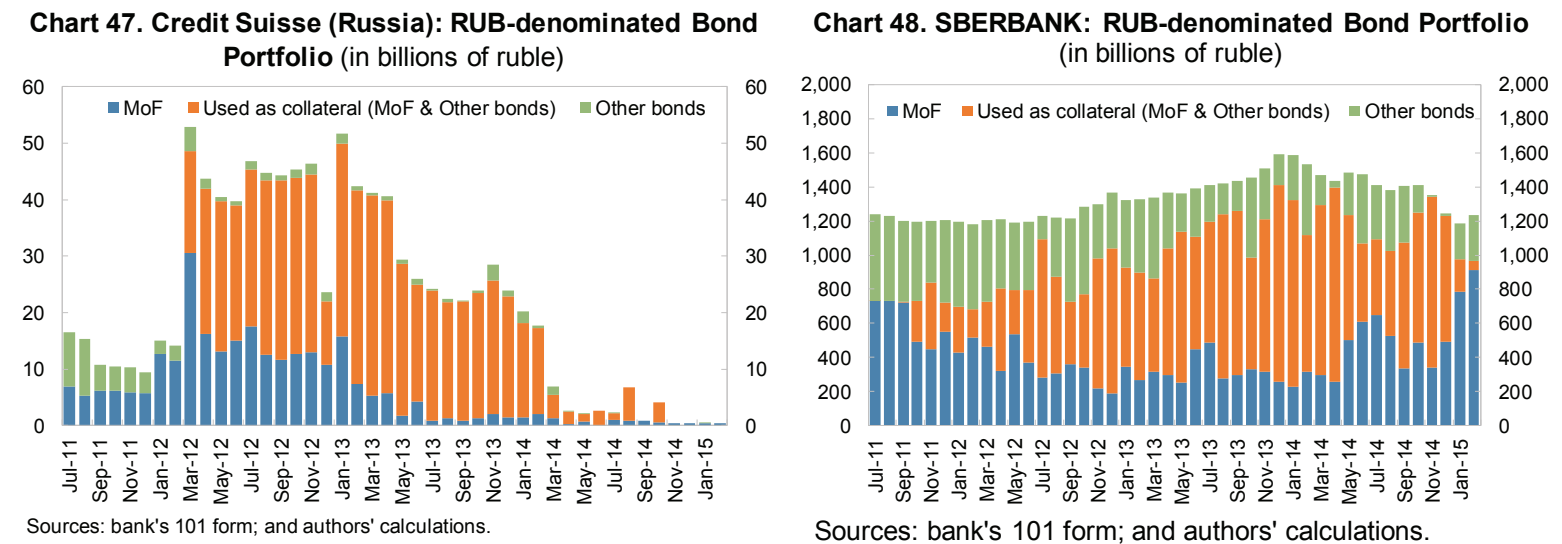

The involvement of GIB-subs in domestic fixed-income markets seemed to be limited to OFZ bonds. While GIB-subs and foreigners represented half of the total OFZ turnover, their involvement in domestic corporate and regional bonds was negligible (Charts 49 and 50). This difference is in line with the preference of foreign investors: their interest in other types of bonds is constrained by the need to conduct individual credit analysis and the small domestic issuance size. Given that most high quality and transparent Russian corporates prefer to borrow abroad by issuing Eurobonds, the remaining domestic corporate issuers are typically riskier with much less liquidity. 

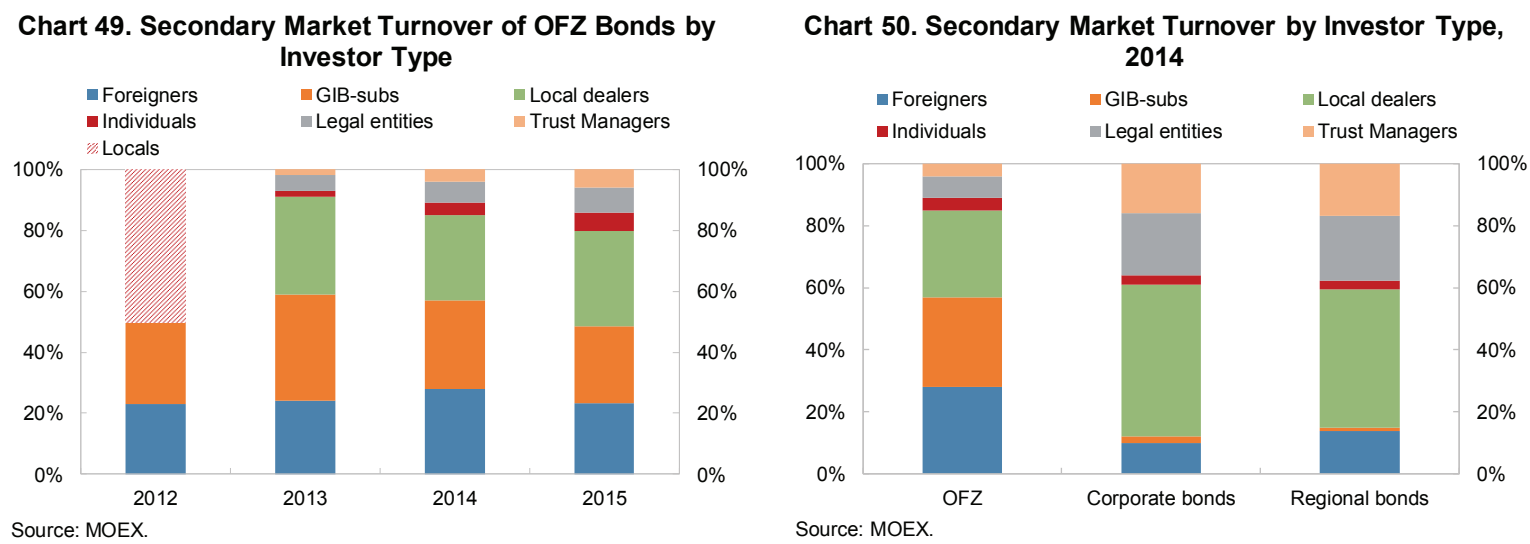

The predominant foreign interest in OFZ bonds caused them to be decoupled from other segments of domestic fixed-income market that have little presence of foreign investors. This disparity of foreign interest contributed to the increased spreads of local bonds to OFZ bonds as the liberalization of the OFZ bond market proceeded (Chart 51). This development led some analysts to conclude that OFZ bonds were overpriced relative to other domestic bonds. Such concern seemed to be validated by the unusual price behavior: during calm periods, Eurobonds' credit spreads declined while domestic credit spreads increased; while the opposite happened when market stress was high (e.g., taper tantrum) (Charts 51 and 52). Such price behavior meant that OFZ bonds might not be treated as a benchmark for efficient valuation of other segments of domestic fixed-income market.
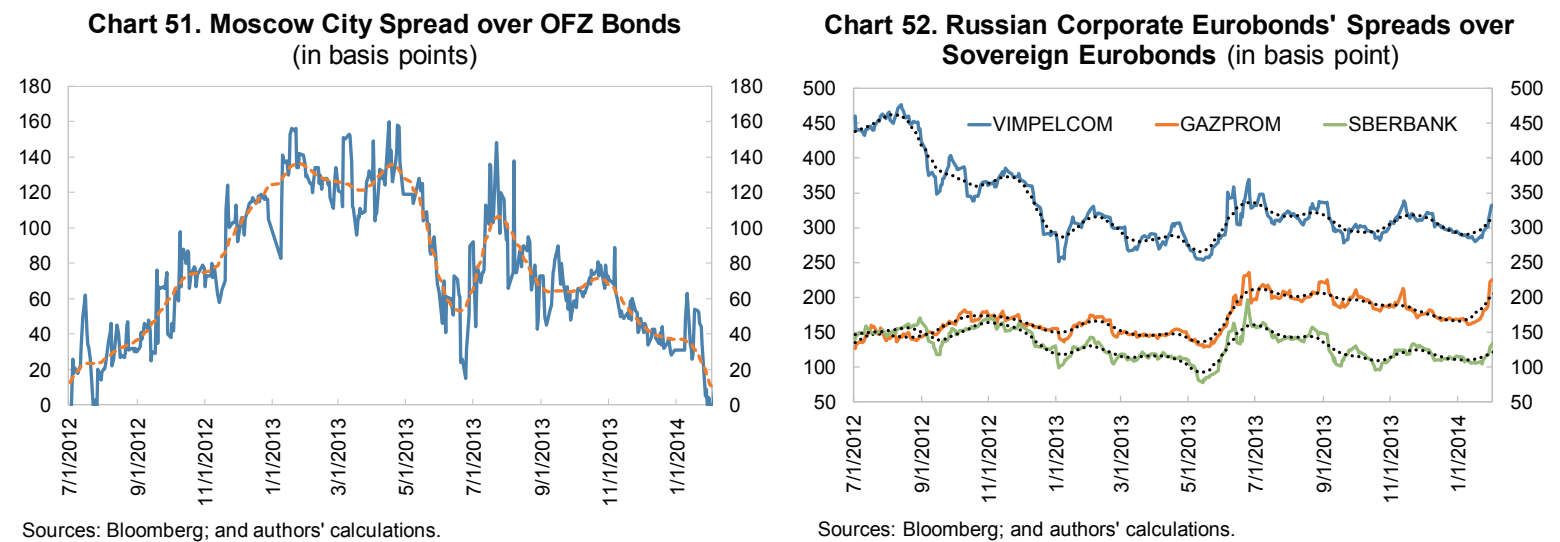

\section{Shocks ANd Market DeVelopments}

Since the liberalization of the OFZ bond market in early 2013, Russia was hit by several shocks. While the taper tantrum in mid-2013 affected a wide class of EM LCY government bonds, OFZ bonds were hit by a couple of Russia-specific shocks: the third round of sanctions (in response to Russia's actions in Crimea and developments in Eastern Ukraine) against Russia's large corporates and banks in the summer of 2014, and credit rating downgrade to speculative category by S\&P and Moody's in January-February 2015. In these episodes of shocks, foreign holdings often recovered quickly and did not destabilize the OFZ bond market while contributing to market development. 


\section{A. Taper Tantrum-May 2013}

When the chairman of the Fed raised the possibility of the Fed tapering its purchase of treasury and agency bonds, many segments of fixed-income universe, including EM LCY bond markets, experienced massive outflows of U.S. retail investors (JPMorgan, 2013). As in other EMs, the taper tantrum led to a sharp foreign sell-off of OFZ bonds and a spike in the secondary market turnover (Charts 53 and 54).
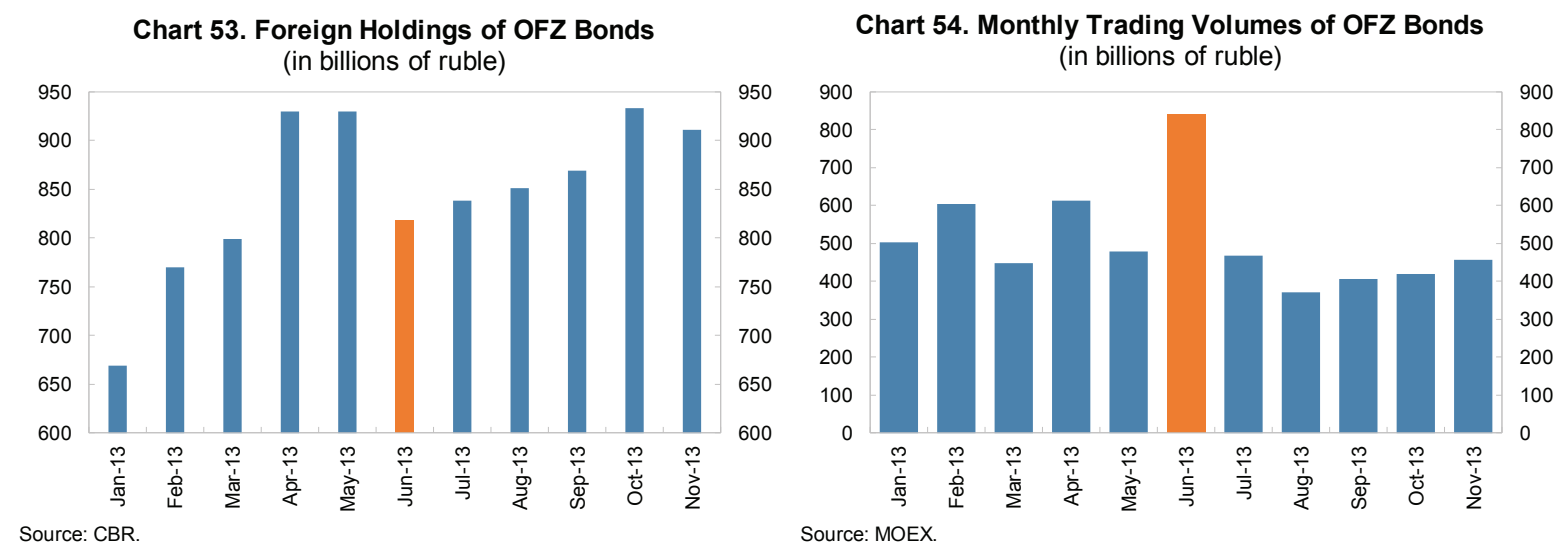

The impact of the sell-offs on the OFZ yield curve was most strongly felt in the medium- and long-term maturity segments. To begin with, foreign position was heavier in these segments than short-term ones (Chart 55), and more dominant if highly illiquid bonds (such as bonds to recapitalize banks) with negligible share of foreign investors were excluded (BCS, 2014). For instance, in the 10-15Y segment, foreign share in the stock of actively traded OFZ bonds was 73 percent at end-May 2013 (Chart 56). On the top of this, given that domestic banks' holdings of long-term OFZ bonds are partially immobilized in repo operations with the CBR and that many institutional investors have a buy-and-hold strategy, the dominance of foreign investors in longer-term segments became more pronounced. Consequently, in a onedirectional sell-off by foreign investors, yields of longer-term bonds were affected more than those of shorter-term bonds, corresponding to a sharper spike in bonds' term spread (Chart $57)$.

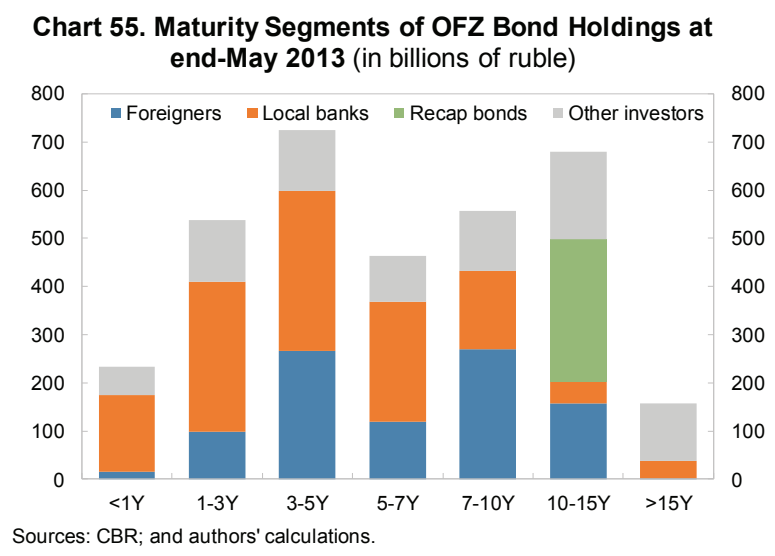

Chart 56. Share of Foreign Investors in OFZ Bonds at endMay 2013

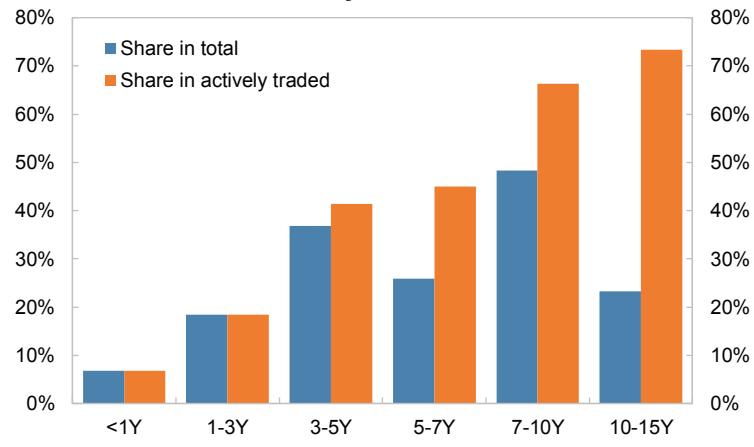

Sources: Bloomberg; CBR; and authors' calculations. 
Foreign sell-off was absorbed by domestic banks (Chart 58) as the enormous yield spike made the valuations of bonds more attractive (valuations move inversely with yields). In addition, their purchase could help to support the valuation so as to curb the size of unrealized losses of their existing bond position.
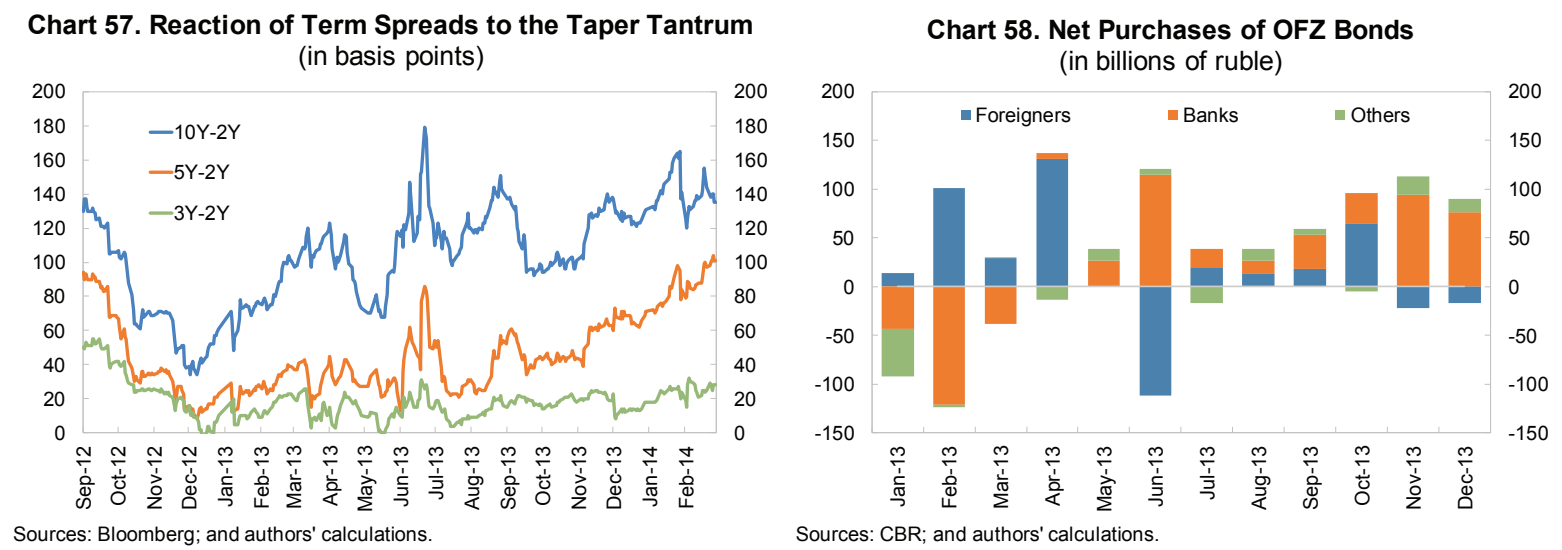

Overall, the longest-term segments showed the largest net sales of foreign investors measured by the share of the outstanding actively traded OFZ bonds (Chart 59). However, they recovered very quickly when the acute period of the taper tantrum was over while this was not the case for the medium-term segments (Chart 60).

As the longer-term segments recovered, foreign holdings recovered to the pre-taper tantrum level. This was in contrast to the gradually declining AUM benchmarked to GBI-EM indices (JPMorgan, 2014b), which may indicate that while U.S. retail investors sold their positions in EMs, other groups of foreign investors may find it attractive to purchase EM bonds at now higher levels of yields. A potential group is central banks and sovereign wealth funds, especially those of EMs, as EM LCY bonds could provide diversification away from hardcurrency denominated financial instruments while their higher yields reduced the cost of holding FX reserves (Standard Chartered, 2013).

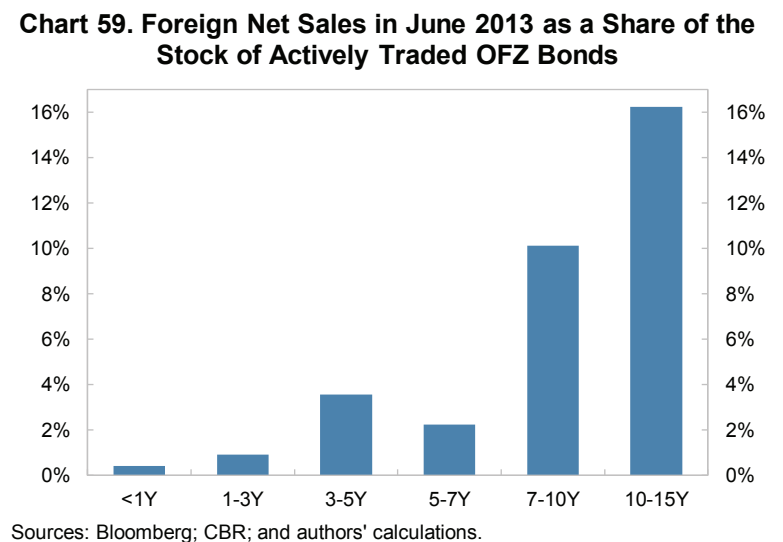

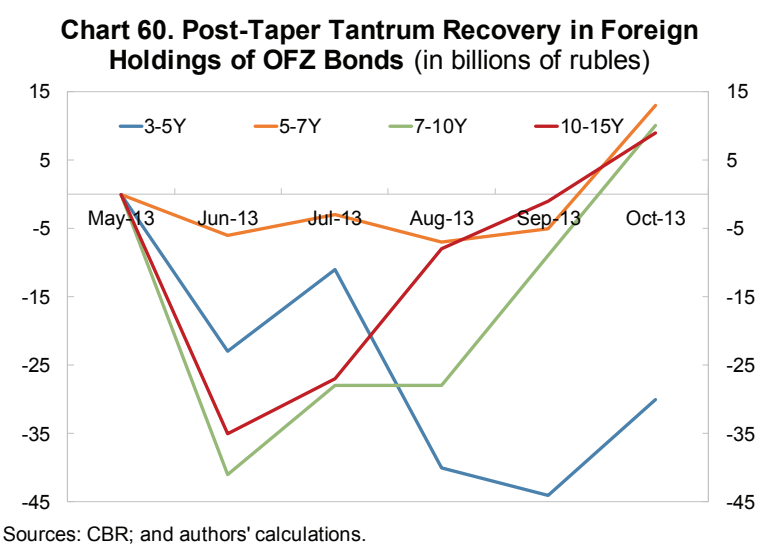




\section{B. The Third Round of Sanctions-Summer 2014}

The third round of sanctions blocked the access of large Russian state-affiliated corporates and banks to global U.S. dollar financing thus constraining their abilities to refinance their external debt. As a response, they tried to accumulate U.S. dollar liquidity to cover not only short-term debt but also long-term one. The CBR was initially unable to satisfy the enormous demand for U.S. dollar liquidity or to calm down the market by assuring buyers that their long-term U.S. dollar liquidity demand would be met when due.

When the CBR tried to smooth the shock, foreign investors intensified the sale of OFZ bonds leading to a large supply in the secondary market. In contrast to the period prior to the sanctions when foreign investors helped to absorb net bond issuance, during this sell-off period, the MOF had difficulty in finding buyers for OFZ bonds (Charts 61 and 62).
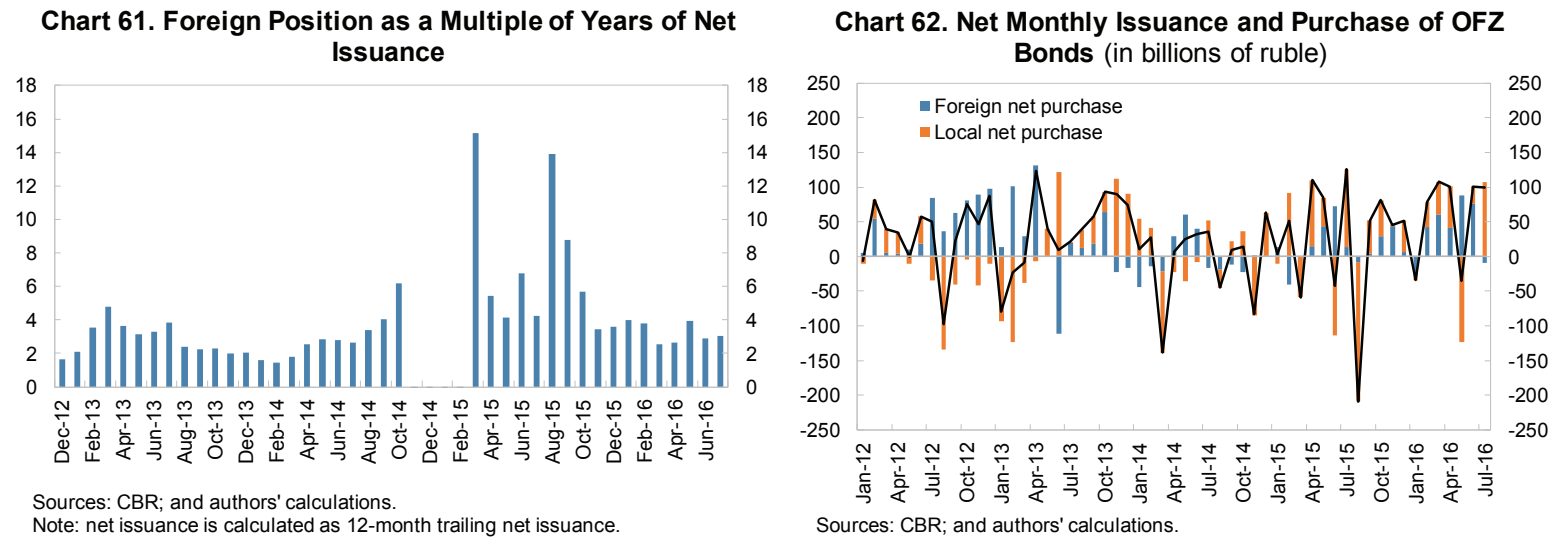

The emergency policy rate hike from 10.5 percent to 17 percent on December 16,2014 became the watershed. Before the hike, despite most models presenting that the ruble was fundamentally undervalued (JPMorgan 2014a), foreign investors were firm in their underweight stance for the ruble, as they were not convinced that the CBR could be able to absorb the enormous demand for U.S. dollar liquidity. In addition, foreign investors became underweight for duration, with bonds pricing further hikes in the nearest future, as investors perceived that the CBR's rate increases (50bps in July and 150bps in November) were not enough to contain the sharply accelerated inflation or to prevent bank deposits from dollarization. These effects led to a substantial reduction of foreign holdings in OFZ bonds which stopped only in December after the emergency hike. 
The emergency hike convinced the market that the CBR was ready to contain inflation at the expense of growth. The CBR's agreement with large SOEs regarding stable supply of U.S. dollars assured the market that the demand for U.S. liquidity would be stabilized. In addition, the CBR expanded FX liquidity facilities by adding new maturities to FX auctions and broadening the definition of eligible collaterals while making these facilities more attractive by reducing interest rates of FX REPOs. These measures had the desired impact, as around December 16, 2014 foreign investors turned their ruble positions from short to long as indicated by the number of open USDRUB futures contracts (Chart 63).
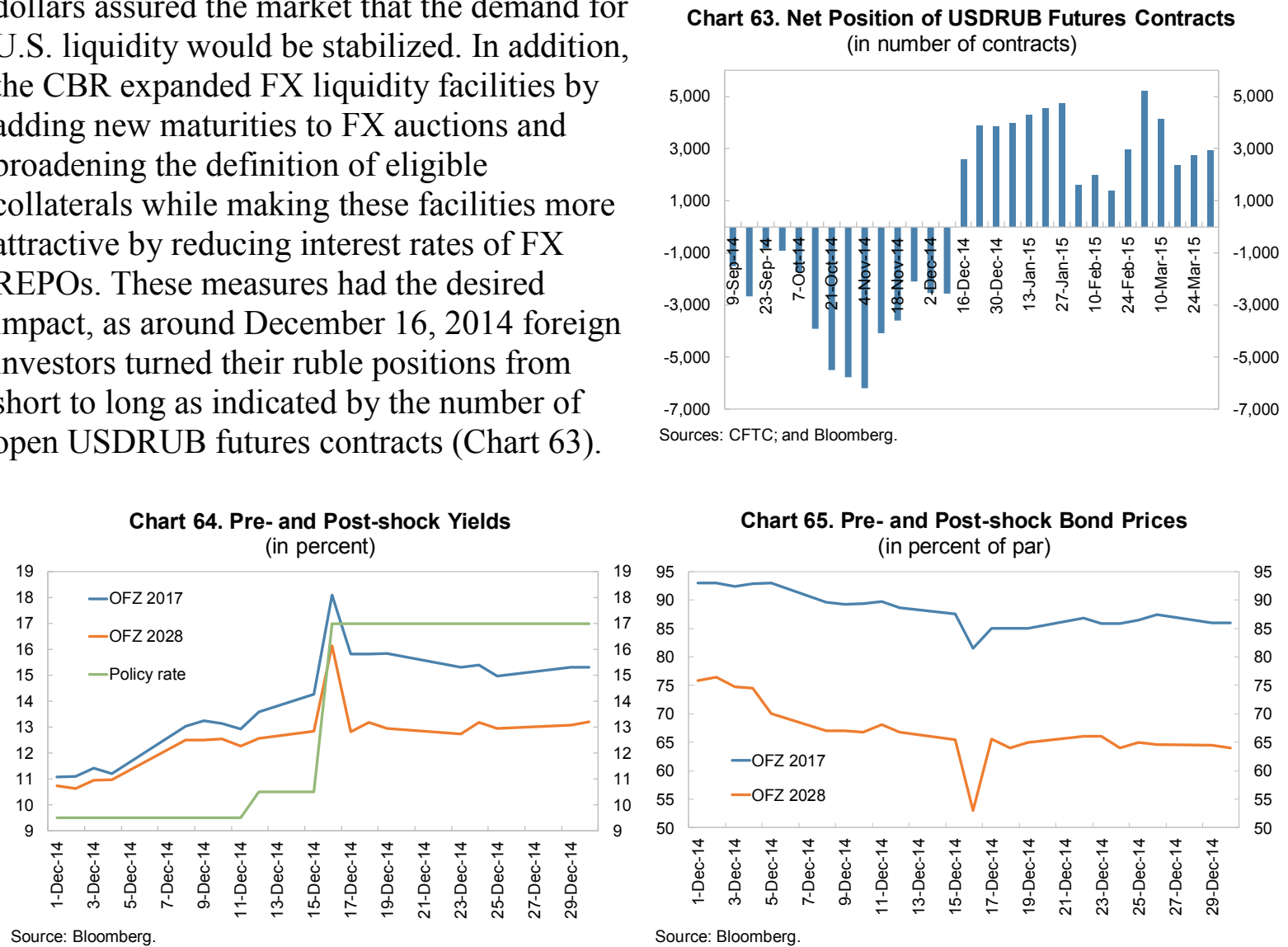

The repricing of OFZ bonds completed within two days. Immediately after the policy rate hike, yields shot to 16-18 percent on the first day before declining to more stable levels on the next day (Charts 64 and 65). The shock did not lead to notable outflows of foreign holdings or any big panic sell-off measured by daily and monthly trading volumes (Charts 66,67 , and 68). Even if some foreign investors decided to reduce or close their positions, post-shock outlook offered multiple sources of returns for other investors to step in: first, the increased rate provided higher return; second, the notably inverted shape of the yield curve implied a strong reduction in future rates and subsequent valuation gains (Chart 69); and third, the policy rate hike would make the real interest rate among the highest across EM, a view validated by the late-introduced inflation-linked bonds (Chart 70).

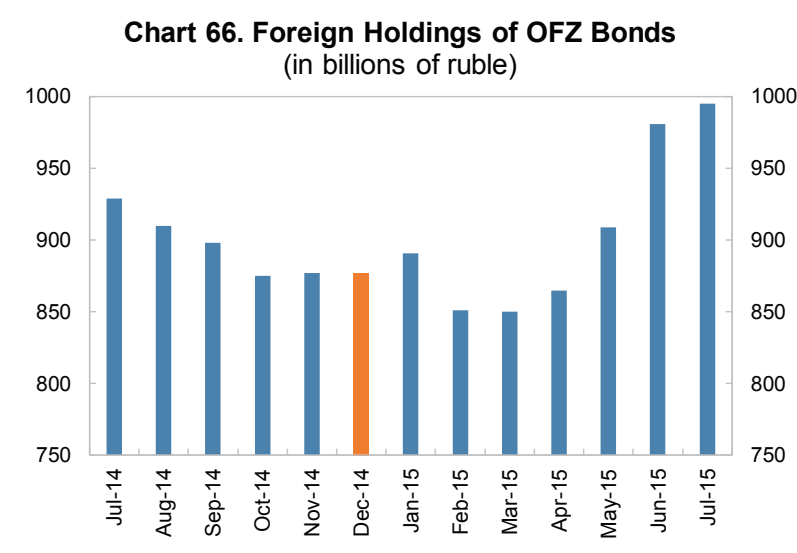

Source: CBR. 


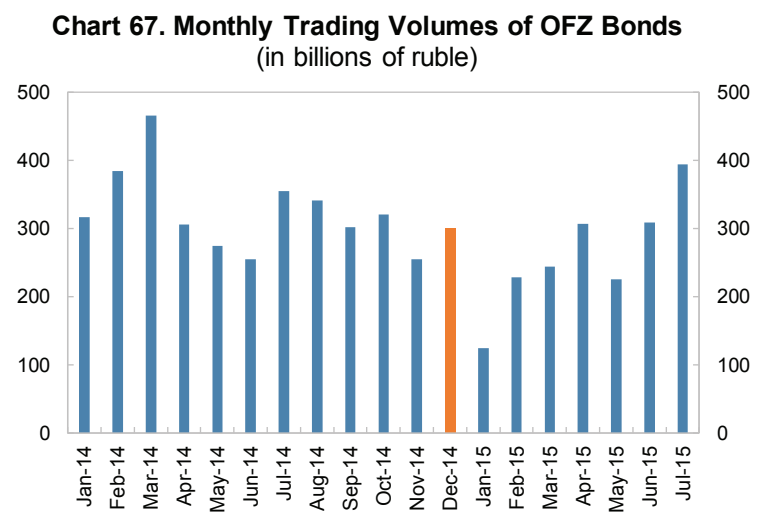
Source: MOEX.

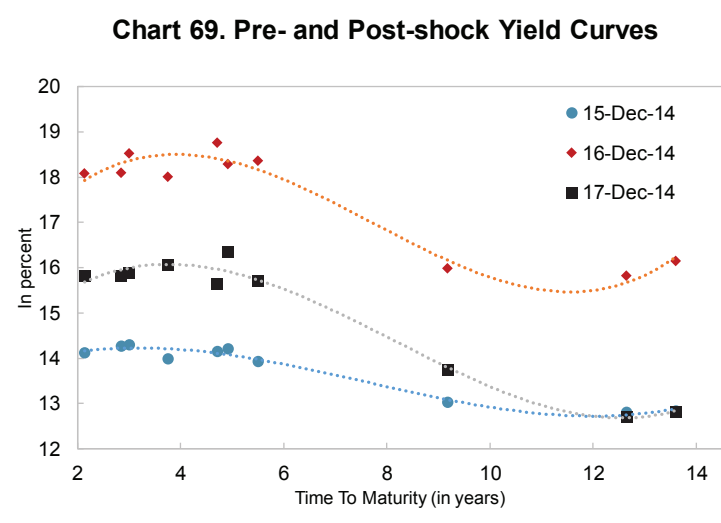

Chart 68. Daily Trading Volumes of OFZ 2023, 2027, and 2028 (in billions of ruble)

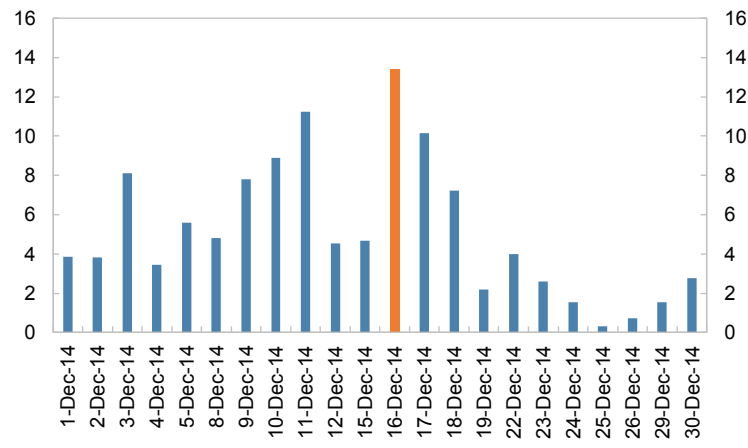

Source: Bloomberg.

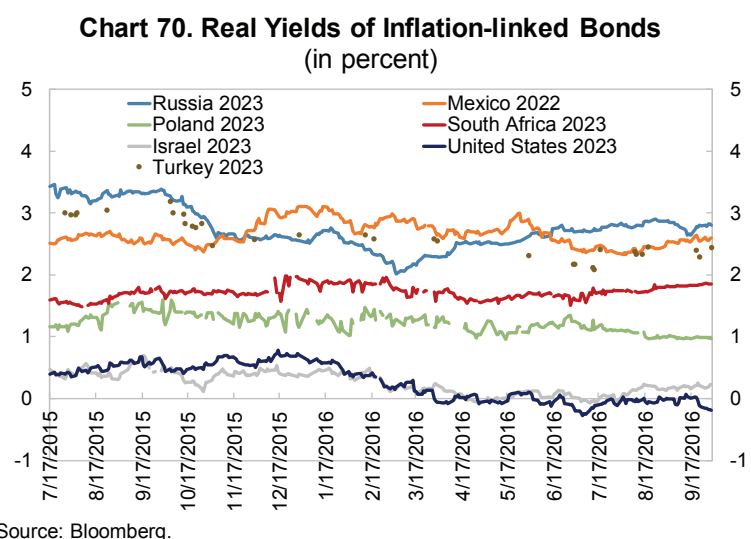

The shock also forced the MOF to introduce new types of OFZ bonds to cater to investor demand, therefore expanding the universe of domestic sovereign fixed-income instruments. In response to market demand to take over interest rate and inflation risks from investors, the MOF started to issue floating-rate and inflation-linked bonds (the so-called "floaters" and "linkers"), thus diversifying the composition of domestic sovereign bonds as in other emerging and developed markets (Chart 71). When the MOF issued floaters and linkers in the mid-2000s, they turned out to be very illiquid with negligible demand from investors. In contrast, those introduced in 2015 were met with considerable demand. Overall, gross placements in 2015 were dominated by these new instruments (Chart 72). Besides direct placements to the market, the MOF issued RUB1 billion of floaters directly to the Deposit Insurance Agency to be later used for capital injection to under-capitalized banks. 


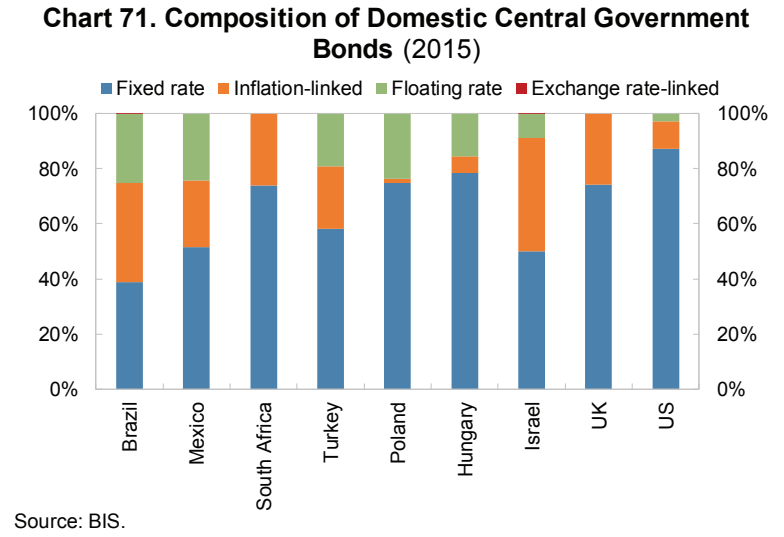

Chart 72. Structure of 2015 Gross Issuance of OFZ Bonds (in billions of ruble)

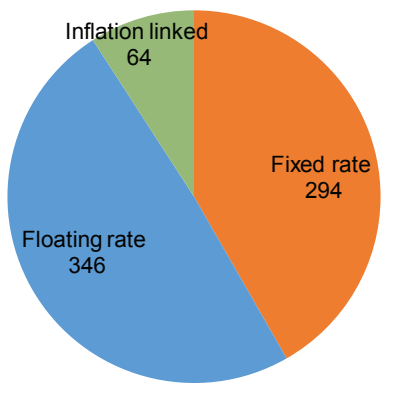

Sources: CBonds; and authors' calculations.

On the supply side, inflation-linked bonds should constitute an essential part of a government's portfolio of liabilities since they allow it to organically match the inflationsensitive part of its revenues with inflation-linked expenses of servicing its debt. On the demand side, they are a natural choice for institutional investors as they offer a protection against inflation. Other investors could build trading based on break-even inflation rate between fixed-rate and inflation-linked bonds. The debut OFZ linkers offered a real yield among the highest across EMs (Chart 70), making them attractive to investors though costly for the government.

In contrast to linkers, floating-rate bonds do not offer a natural match with government's revenue and, compared to fixed-rate bonds, the government carries the interest rate risk. However, their coupon-representing a floating rate index plus a spread-guarantees that banks could receive a stable margin over their (often floating) cost of funding. Such structure allows a government to place sizable amounts of bonds even in periods of high turbulence in fixed-income and money markets as can be seen in the case of Brazil (Chart 73). In 2015, the MOF in Russia placed a number of floaters referencing 6month average of the RUONIA index (Ruble Overnight Index Average).

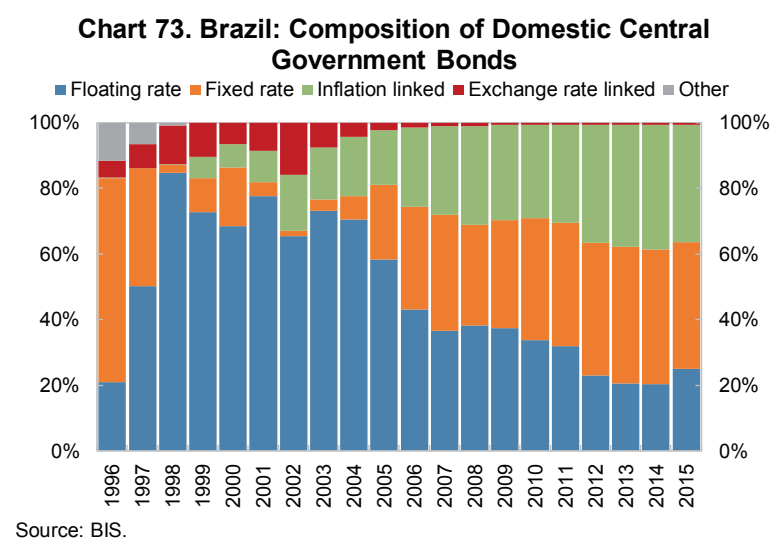

\section{Rating Downgrade-Early 2015}

A bond rating downgrade could trigger investors to reduce their holdings of that bond. Such a reconsideration of riskiness would typically lead to a new yield premium to cover the increased risk. Investors may reduce their holdings in order to maintain the position within the pre-specified limit of risk allocation. If there is no change in the supply of bonds, the repricing could attract another group of more risk-tolerant investors.

The S\&P and Moody's downgrade of Russia's credit rating from investment grade (IG) category to speculative category in January-February 2015 could have affected foreign 
holdings of OFZ bonds. For those with IG mandate, they had to close their positions in response to the downgrade.

The positions of investors with IG mandate seemed to be rather small. For example, in December 2014, the AUM benchmarked to the GBI-EM Global Diversified IG-only index was about US\$5-7 billion while the AUM of the GBI-EM Global Diversified index was almost US\$200 billion (JPMorgan, 2014c). Such low allocation to the IG-only index may be partly explained by the fact that most constituents of the index are only a few notches above the speculative grade and for a strategic long-term EM local currency allocation it may be practically unfeasible to comply with the IG-only rule, as it is highly possible that some of the countries will temporally slip back into the speculative rating category.

It is highly likely that most foreign investors of OFZ bonds are tolerant to temporary drops in credit rating. Given the high share of oil and gas in Russian government's total revenue, investors are aware that the government's creditworthiness is heavily influenced by global oil prices. In addition, for a high-beta commodity currency such as ruble, the dominance of foreign exchange component (highly influenced by the oil prices) in the total return of OFZ bonds eclipses the impact of a credit event and the associated yield jump (though the credit event and foreign exchange, both influenced by oil prices, often co-move) (Charts 74 and 75).
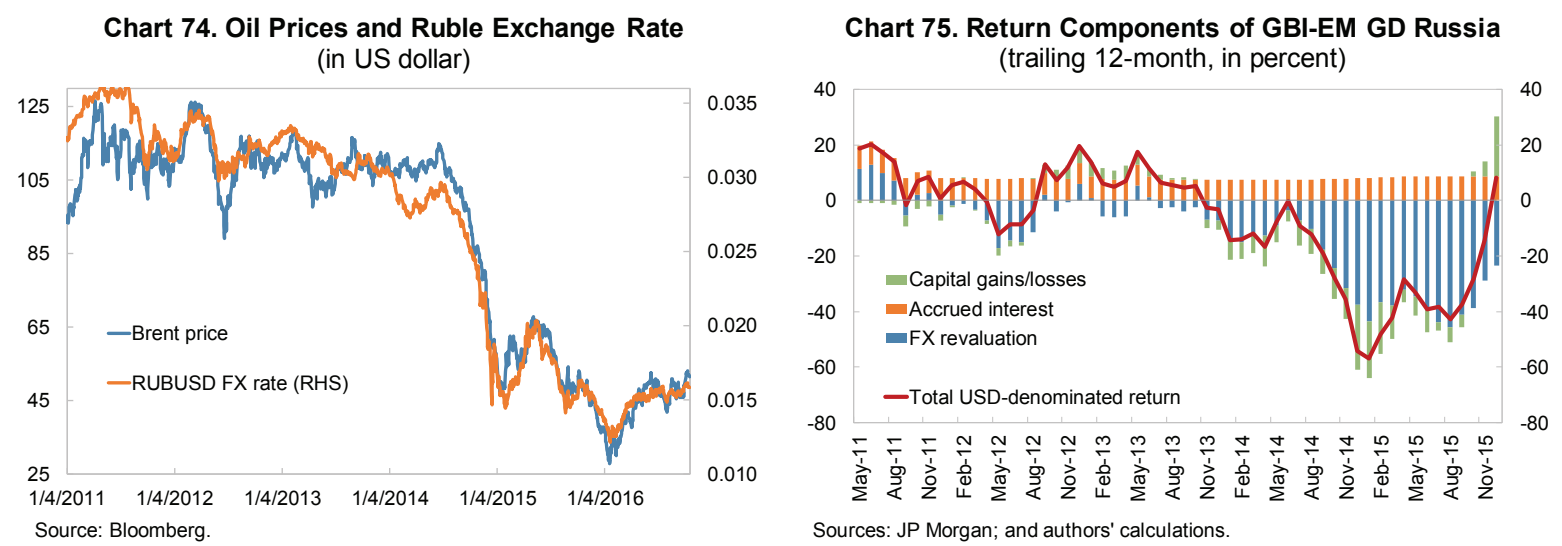

\section{Conclusion}

The history of the OFZ bond market contains the imprints of all major events occurring along the development of financial markets in Russia. Various global investors are searching for yield in this country with significant potential which occasionally could be hit by economic and geopolitical shocks. When the market was relatively closed, foreign investors were able to influence the market through offshore transactions, or to gain market exposure through financial derivatives and other proxies. When the market was in the process of opening up, foreign market makers preemptively positioned themselves to benefit from the expected increasing foreign demand for OFZ bonds. The ultimate liberalization integrated the OFZ bond market into the global financial system. While financial integration could allow more spillover from global shocks to the domestic market and subject it to fickle global market sentiment, it could also bring opportunities for the market to grow, enhance the mechanism 
for price discovery, and improve the allocation of resources. The integration into global financial markets has also raised the bar for transparency and credibility of the policy framework.

The experience of the OFZ bond market can be applied to other EMs. EM financial assets have become one of the key investment classes. Even for those with relatively closed capital account or closed infrastructure, foreign investors can always find ways to circumvent national border and gain access to domestic financial assets if they find them attractive. Gradually opening the market while improving the institutional and policy framework to enhance financial system's resilience to shocks could help the domestic authorities to better monitor the behavior of foreign investors, and be prepared when the next shocks hit, and then continue to enhance the policy framework and deepen the financial market development. 


\section{References}

Ahmed, Shaghil, and Andrei Zlate, 2013, "Capital Flows to Emerging Market Economies: A Brave New World?” International Finance Discussion Papers, Board of Governors of the Federal Reserve System, Number 1081.

Arslanalp, Serkan and Takahiro Tsuda, 2012, "Tracking Global Demand for Advanced Economy Sovereign Debt," IMF Working Paper 12/284 (Washington: International Monetary Fund).

Arslanalp, Serkan and Takahiro Tsuda, 2015, "Emerging Market Portfolio Flows: The Role of Benchmark-Driven Investors,” IMF Working Paper 15/263 (Washington: International Monetary Fund).

BCS, 2014, “OFZ: Foreigners prefer longer bonds”, BrokerCreditService, May-2014.

Comelli, Fabio, 2012, "Emerging Market Sovereign Bond Spreads: Estimation and Backtesting," IMF Working Paper 12/212 (Washington: International Monetary Fund).

Credit Suisse, 2012, "Russia: A New Era for the Local Bond Market,” March 9, 2012.

Csonto, Balazs and Iryna Ivaschenko, 2013, "Determinants of Sovereign Bond Spreads in Emerging Markets: Local Fundamentals and Global Factors vs. Ever-Changing Misalignments," IMF Working Paper 13/164 (Washington: International Monetary Fund).

Deryugina, Elena, Olga Kovalenko, Irina Pantina, and Alexey Ponomarenko, 2015, "Disentangling Loan Demand and Supply Shocks in Russia," Central Bank of Russia, Moscow, 2015.

Drobyshevskiy, Segery, Lugovoy Oleg, Ekaterina Astafieva, and Natalia Burkova, 2009, "Modeling the term structure of interest rates on Russian government bonds in 20002008," Institute of the Economy in Transition, Working Paper, Mosco, Russia, 2009.

Ebeke, Christian and Yinqiu Lu, 2015, "Emerging Market Local Currency Bond Yields and Foreign Holdings - a Fortune or Misfortune?" Journal of International Money and Finance, 59 (2015), 203-219.

Euromoney, 2012, "SocGén Urges Investors to Hop on RUB Bandwagon; Liberalization a Game Changer," Euromoney, October 25, 2012.

Forbes, 2011, "MICEX and RTS Shareholders have Signed a Letter of Intent," Forbes, February 3, 2011. 
Gazprobank, 2014, "RUB-denominated Corporate Bonds: What Foreigners will Get?" Gazprombank, January 2014.

Gurvich, Evsey, Vladimir Sokolov, and Alexey Ulyukaev, 2009, "Analysis of the Relationship Between the Exchange Rate Policy of the Russian Central Bank and the Interest Rates: Uncovered and Covered Parity", Journal of the New Economic Association, 1-2, 2009.

International Monetary Fund, 2012, "Global Financial Stability Report: Restoring Confidence and Progressing on Reforms," October 2012 (Washington: International Monetary Fund).

JPMorgan, 2013, “Great Rotation: Myth or Reality?” November 4, 2013.

JPMorgan, 2014a, “Russia: Searching Through the Ruble,” October 31, 2014.

JPMorgan, 2014b, "Emerging Markets Corporate Outlook and Strategy," November 26, 2014.

JPMorgan, 2014c, "Russia: Special report,” December 18, 2014.

Jaramillo, Laura and Anke Weber, 2012, "Bond Yields in Emerging Economies: It Matters What State You Are In," IMF Working Paper 12/198 (Washington: International Monetary Fund).

Ministry Of Finance Of The Russian Federation, 2011, "Public Debt Management Policy Of The Russian Federation For 2012 - 2014,” Moscow, Russia, 2011.

Miyajima, Ken and Ilhyock Shim, 2014, "Asset Managers in Emerging Market Economies," BIS Quarterly Review, September, 2014.

NAUFOR, 2014, “Russian Securities Market: 2014,”NAUFOR, 2014.

Noel, Michel, Zeynep Kantur, Evgeny Krasnov, and Sue Rutledge, 2006, "Development of Capital Markets and Institutional Investors in Russia," World Bank Working Paper No.87 2006.

Raddatz, Claudio, Sergio Schmukler, and Tomós. Williams, 2015, "International Asset Allocations and Capital Flows: The Benchmark Effect," HKIMR Working Paper No. $04 / 2015$.

Reuters, 2012, "Foreign investors rushed for Russian government bonds," Reuters, February $9,2012$. 
Sahay, Ratna, Vivek Arora, Thanos Arvanitis, Hamid Faruqee, Papa N'Diaye, Tommaso Mancini-Griffoli, and an IMF Team, 2014, "Emerging Market Volatility: Lessons From The Taper Tantrum," IMF Staff Discussion Note No. 14/09.

Sienaert, Alex, 2012, "Foreign Investment in Local Currency Bonds: Considerations for Emerging Market Public Debt Managers," World Bank Policy Research Working Papers No. 6284.

Standard Chartered, 2013, "Local Markets Compendium 2013."

Yudaeva, Ksenia, Nadezhda Ivanova, Konstantin Kozlov, and Marina Kamenskih, 2009, "The Dynamics of Lending to a Shrinking Economy: the Credit Crunch and the Fall in Demand for Loans?" SBERBANK, Moscow, 2009. 